\title{
Feasibility analysis of establishing charging stations for electrical vehicles in public facilities
}

Vivek Komarina

Follow this and additional works at: https://researchrepository.wvu.edu/etd

\section{Recommended Citation \\ Komarina, Vivek, "Feasibility analysis of establishing charging stations for electrical vehicles in public facilities" (2018). Graduate Theses, Dissertations, and Problem Reports. 4005. \\ https://researchrepository.wvu.edu/etd/4005}

This Problem/Project Report is protected by copyright and/or related rights. It has been brought to you by the The Research Repository @WVU with permission from the rights-holder(s). You are free to use this Problem/Project Report in any way that is permitted by the copyright and related rights legislation that applies to your use. For other uses you must obtain permission from the rights-holder(s) directly, unless additional rights are indicated by a Creative Commons license in the record and/ or on the work itself. This Problem/Project Report has been accepted for inclusion in WVU Graduate Theses, Dissertations, and Problem Reports collection by an authorized administrator of The Research Repository @ WVU. For more information, please contact researchrepository@mail.wvu.edu. 
Feasibility Analysis of Establishing Charging Stations For Electrical Vehicles in Public Facilities

Vivek Komarina

Problem Report Submitted

To the Benjamin M. Statler College of Engineering and Mineral Resources

At West Virginia University

in partial fulfillment of the requirements for the degree of

Master of Science in

Industrial Engineering

Bhaskaran Gopalakrishnan, Ph.D., P.E., Chair

Ashish Nimbarte, Ph.D.

Hailin Li, Ph.D.

Department of Industrial and Management Systems Engineering

Morgantown, West Virginia

2018

Keywords: Electric Vehicle Charging Stations, Plug-in Electric Vehicles, Energy Consumption and Costs

Copyright [2018] [Vivek Komarina] 


\begin{abstract}
Feasibility Analysis of Establishing Charging Stations For Electrical Vehicles in Public
\end{abstract}

Facilities

\title{
Vivek Komarina
}

To overcome the transportation sector's dependency on fossil fuels, electric vehicles appears to be a better alternative with a number of impressive benefits. Enhancing the utilization of electric vehicles not only reduces global gasoline and diesel consumption but also helps in running an environmentally cleaner road transport system with zero tailpipe emissions. As road transport involves substantial gasoline and diesel consumption, Plug-in Electric Vehicles (EVs) being more energy efficient and environment friendly can have direct impact on reduction of fuel reliance. One of the important limitations influencing the penetration of electrical vehicles in the global market is the lack of adequate charging infrastructure availability. Considering various challenges involved in deployment of charging infrastructure, enhancement of public charging infrastructure can be a successful step resulting in electric vehicle market raise.

This project is focused in developing a decision support system to evaluate optimal number of charging stations to be established in a public facility, which are sustainable and economically viable. This system considers a Monte Carlo simulation of a scenario using various pre-recorded categorical data, depicting traffic arrival patterns and logistic challenges created by variance in weather severity and time of the year. The simulated data can be used to estimate the energy consumption and costs incurred by the charging stations in the facility. This work results in a decision making spreadsheet-based model that enable facilities to explore cost implications of installing and operating Electric Vehicle Supply Equipment (EVSE). 


\section{Acknowledgment}

Firstly, I would like to express my sincere gratitude to Dr. Bhaskaran Gopalakrishnan, for his continued support and encouragement during the course of my research work.

I would like to thank Dr. Ashish Nimbarte for his interest in me at every stage of the research. His inspiration, timely suggestion with kindness, enthusiasm and energy have enabled me to complete my problem report.

Also, I wish to thank Dr. Hailin Li for his advice and support.

Finally, I thank God, my family and friends for their constant support. 


\section{Table of Contents}

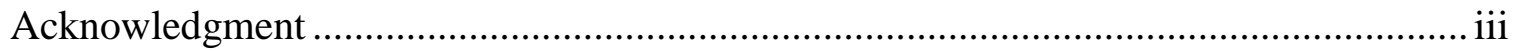

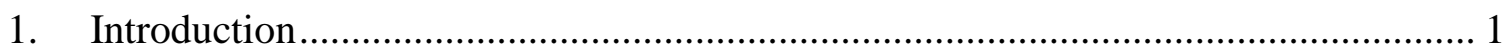

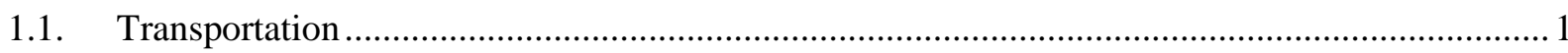

1.1.1. Transportation enabled growth, \& Personal transport: .................................................. 1

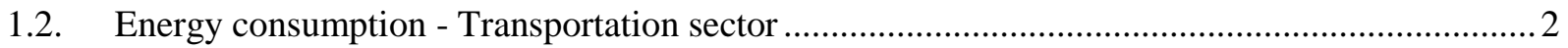

1.3. Petroleum resources' scarcity - Environmental \& Economic impact ....................................... 3

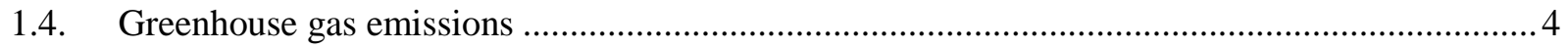

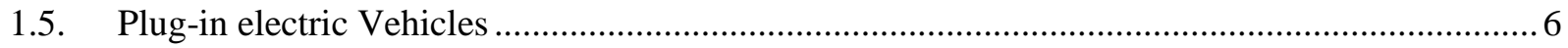

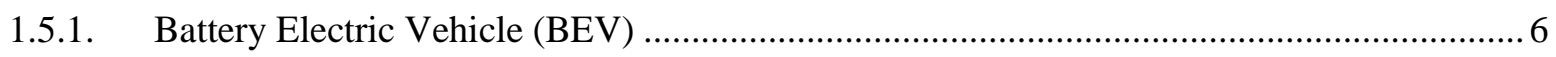

1.5.2. Plug-in Hybrid Electric Vehicle (PHEV) ................................................................... 7

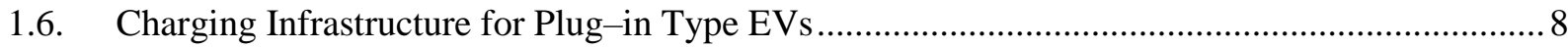

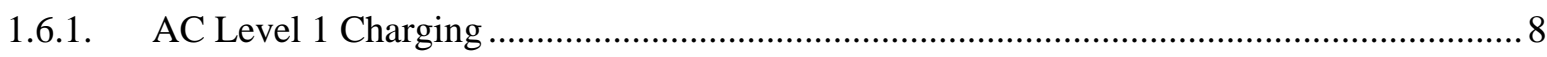

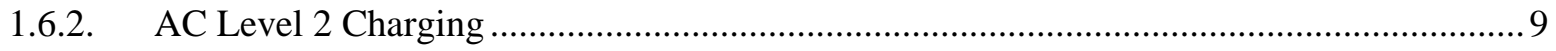

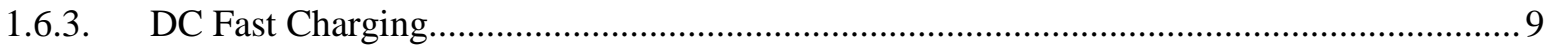

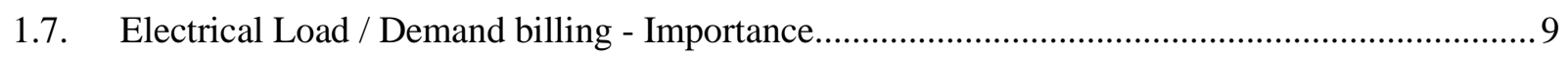

1.8. The Plug-In Electric Vehicle (PEV) Market - Need for EVSE Establishment .......................... 10

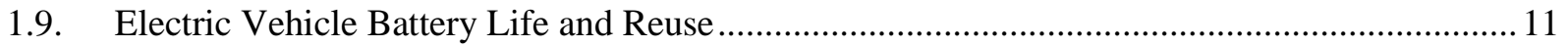

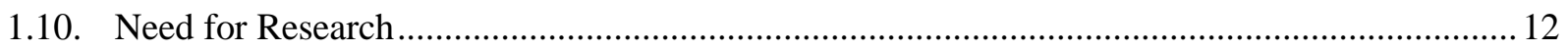




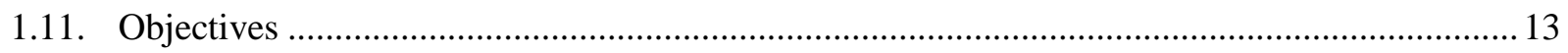

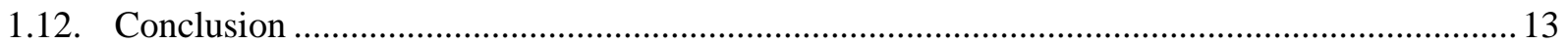

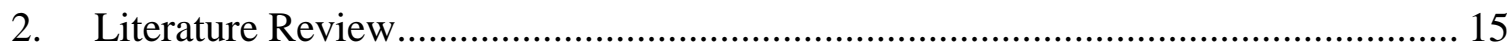

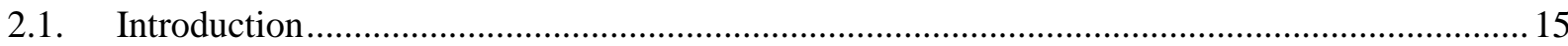

2.2. Lack of adequate Charging Infrastructure as a Prevailing Problem......................................... 16

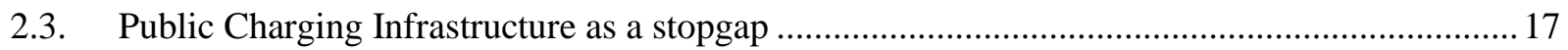

2.4. Role of Public incentives in EV adaption ......................................................................... 18

2.5. Different Models forecasting EV arrival And Charging Patterns ......................................... 20

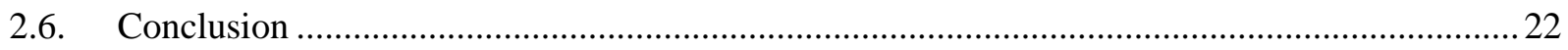

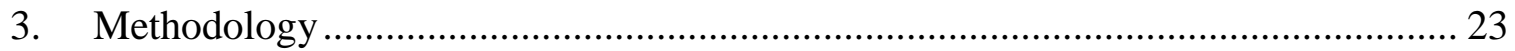

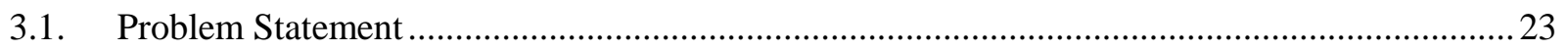

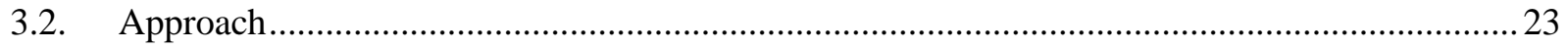

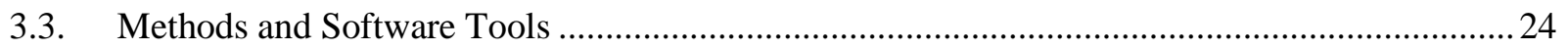

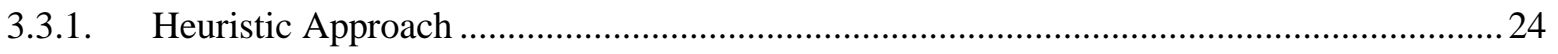

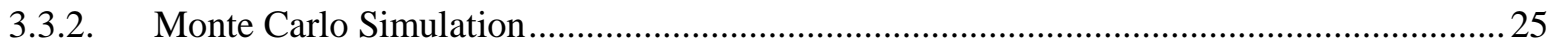

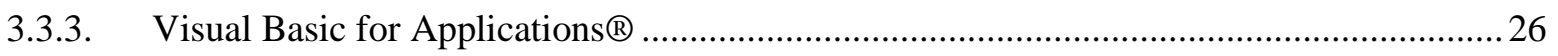

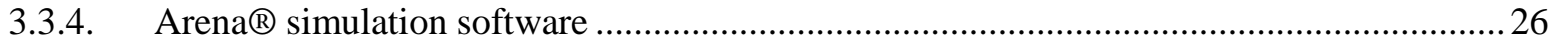

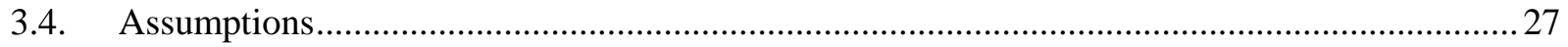

3.5. Electric Vehicle arrival pattern spreadsheet model...........................................................2 


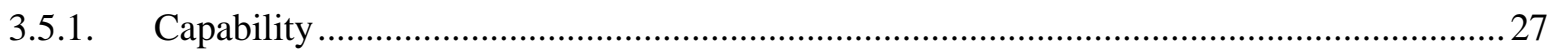

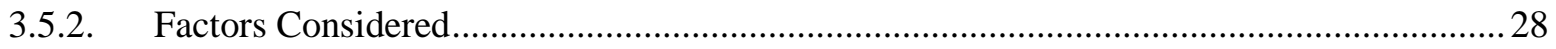

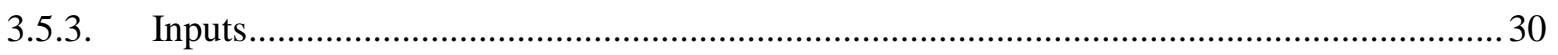

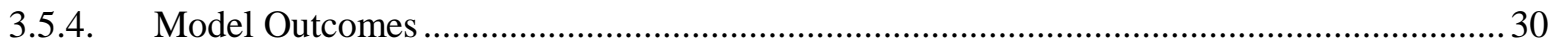

3.6. Charging Pattern and Logistics Modelling Simulation ........................................................... 32

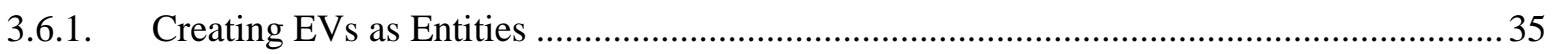

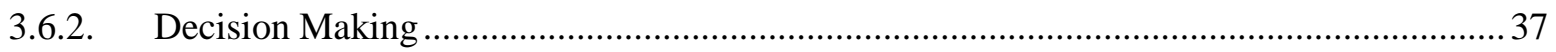

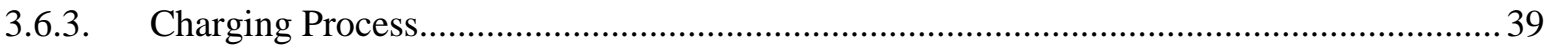

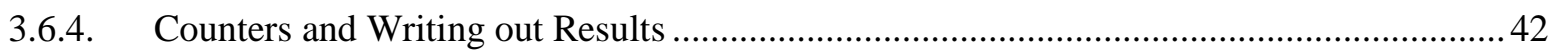

3.7. Annual Energy Costs and Electrical Demand Estimates ......................................................4 44

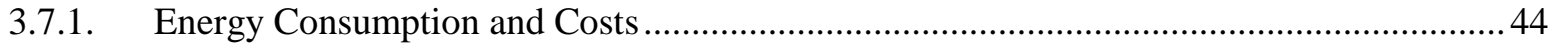

3.7.2. Electrical Peak Load and Demand Costs ........................................................................ 45

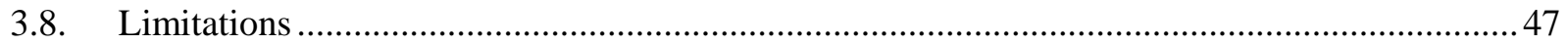

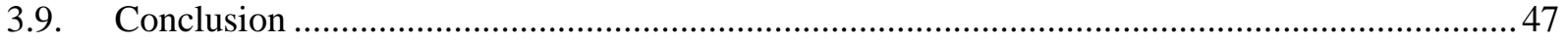

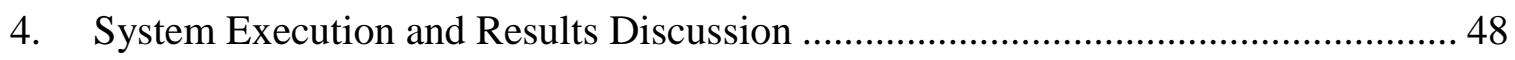

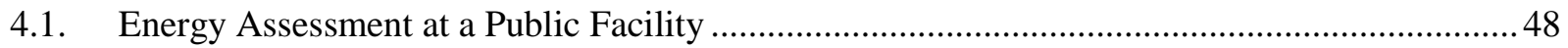

4.2. Electric Vehicle arrival pattern spreadsheet model with Sample Inputs ................................. 48

4.3. Charging Pattern and Logistics Modelling Simulation with Sample Inputs ............................51

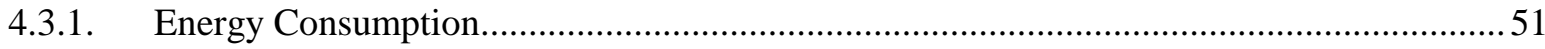

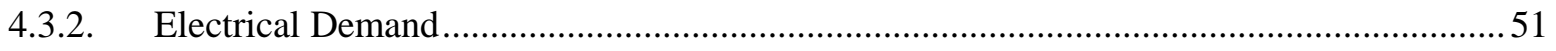




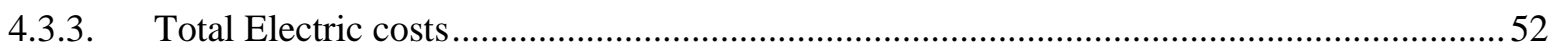

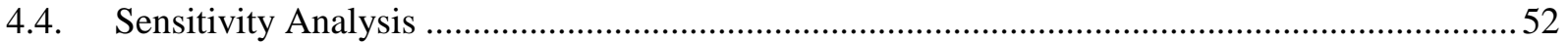

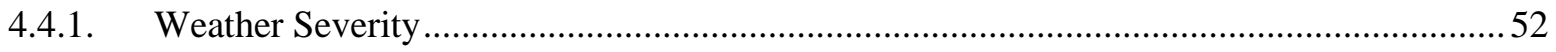

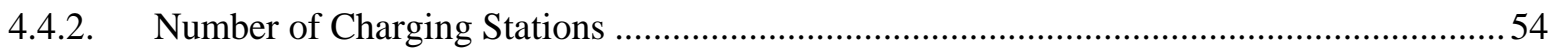

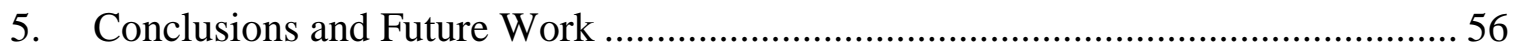

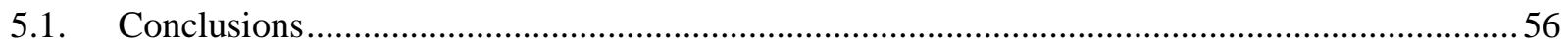

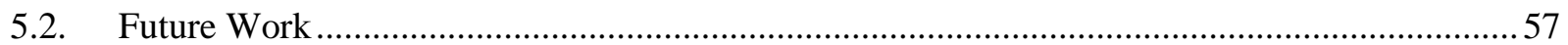

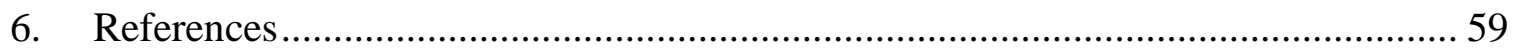

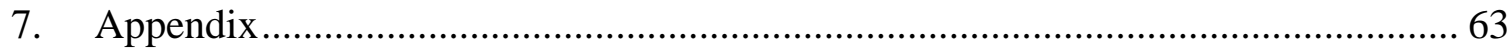

\section{List of Figures}

Figure 1.1. 2015 U.S. GHG Emissions by Sector [4] ................................................... 5

Figure 1.2. 2015 U.S. Transportation Sector GHG Emissions by Source [4] ........................... 5

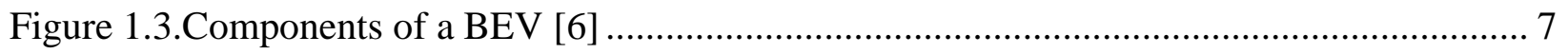

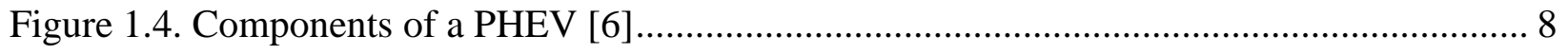

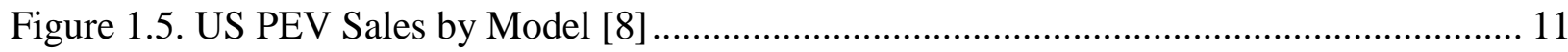

Figure 3.1. Charging Pattern and Logistics Modelling Simulation ....................................... 34

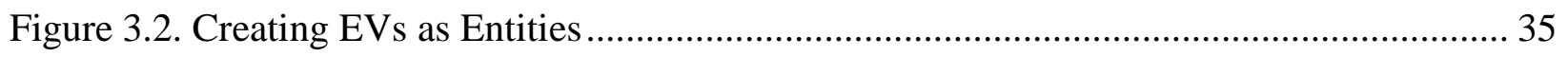

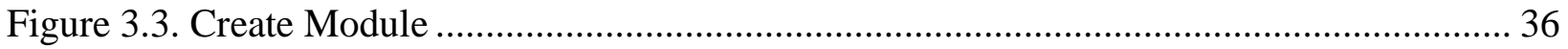


Figure 3.4. Assign module 36

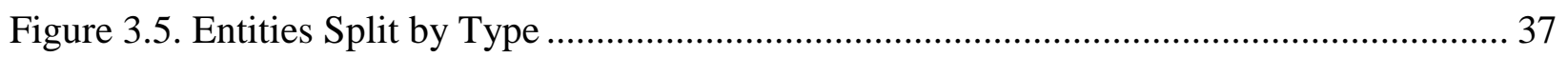

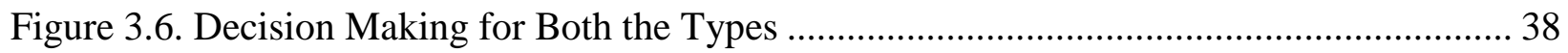

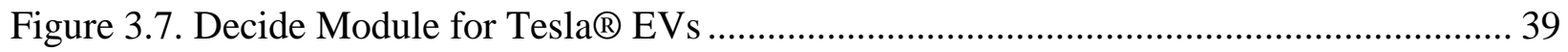

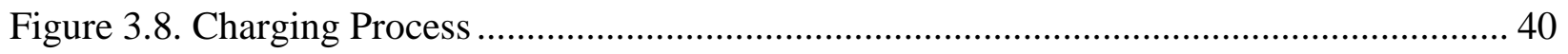

Figure 3.9. Charging Process Module for Schneider ${ }^{\circledR}$ Type ............................................... 41

Figure 3.10.Charging Process Module for Tesla ${ }^{\circledR}$ Type ........................................................ 41

Figure 3.11. Resources Involved in the Model ................................................................. 42

Figure 3.12. Record, Read/Write, and Dispose Modules ................................................ 43

Figure 4.1. Input Boxes for EV Arrival Pattern ............................................................ 49

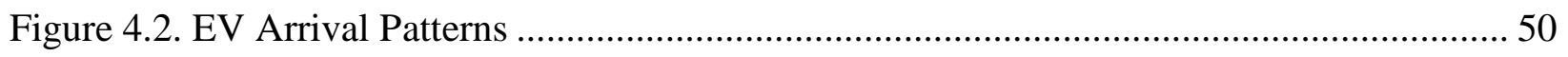

Figure 4.3.Histogram representing Monthly EV Arrivals .............................................. 50

Figure 4.4. Monthly peak Demand Vs Weather Severity ................................................ 53

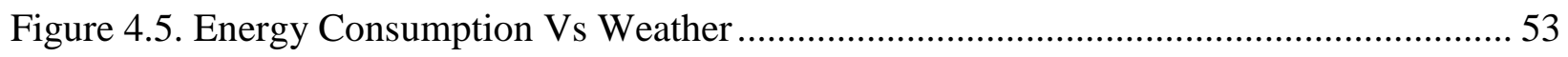

Figure 4.6. Total Monthly Costs Vs Weather .............................................................. 54

Figure 4.7. Peak Demand Vs Number of Charging Stations ............................................. 55

Figure 4.8. Energy Consumption Vs Number of Charging Stations ..................................... 55

Figure 4.9. Total Monthly Costs Vs Number of Charging Stations ....................................... 56 


\section{$\underline{\text { List of Tables }}$}

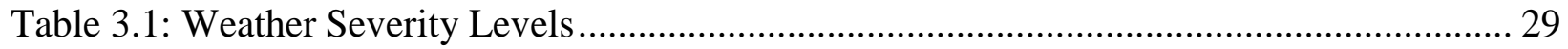

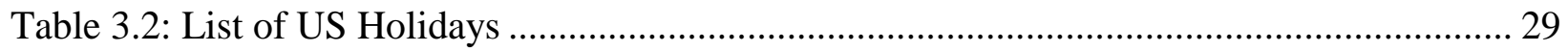

Table 3.3: Number of Electric Vehicles' Outcome Levels ................................................... 31

Table 3.4.Rate structure for the Facility Considered ............................................................. 45 


\section{Introduction}

\subsection{Transportation}

Transportation is movement of people and goods from one place to another. Over time, it has become a social utility by lessening the geographical distance. Contribution of transportation in social, economic, cultural and political grounds facilitated significant development in evolution of human civilization. It would be a completely different situation if there was no progress in improving means of transportation.

\subsubsection{Transportation enabled growth, \& Personal transport:}

Proper development of agricultural sector is made possible only with the support of transportation. Without improvement in transportation, rapid growth in industrialization may not be feasible. Distribution or mass production is achieved with its promising presence. Also physical distribution of finished goods to consumers from production location is made easier and hence played an integral role in marketing. Simultaneously, it has social, cultural and political influence on the society in addition to the economic growth. Foreign travel is made easier with advancements in transportation and resulted in improved connections overseas. Improved connections and globetrotting facilitated broadening knowledge and expertise in various sectors. National integration is reinforced with expansion of transportation and its presence as a cultural and social utility.

Personal transport is a luxury in the beginning of the $20^{\text {th }}$ century. Over years, advancements in mass production and changes in human needs, turned this luxury into an affordable necessity. The total number of cars used by residents of cities and sub urban areas in United States multiplied exponentially from 8 thousand cars in 1900 to 8 million in 1920 and more than 220 million by the year 2000. This generated mobility and accessibility in lives of all sections of people on a scale 
never known before. And hence has boundless impact on living habits and customs of people indirectly.

\subsection{Energy consumption - Transportation sector}

According to United States Energy Information Administration (U.S. EIA) [1], 25\% of total global delivered energy consumption is by transportation sector for moving people and goods. The United States (US), European countries in the Organization for Economic Co-operation and Development (OECD), and China are the major transportation energy consumers and together they account for $55 \%$ of world transportation energy consumption. The transportation energy consumed by the United States in 2012 is 26 quadrillion Btu equivalent, representing the above $25 \%$ of global transportation energy demand.

Earth's transportation energy consumption is being overshadowed by two fuels: gasoline and diesel. These two fuels collectively accounted for $75 \%$ of total delivered transportation energy use in 2012. The US transportation sector exhibits similar trend in fuel consumption with a major 55\% by gasoline and a significant $21 \%$ by diesel. Light-duty vehicles accounting for the largest share of transportation energy consumption, dominate all modes of transportation in most of the world. The United States, with ubiquitous on-road passenger travel was the world's prime transportation energy consumer in 2012. Light-duty vehicles' dominate other means of transport in US with approximately $58.6 \%$ [2] of the US petroleum consumption. Petroleum products account for the largest share of transportation energy use by far, while nonpetroleum fuels account for a small portion of the world energy mix, with natural gas and electricity together accounting for about $4 \%$ of the world's total transportation energy consumption. 


\subsection{Petroleum resources' scarcity - Environmental \& Economic impact}

Continuous consumption of fossil fuels for transportation, electricity and heat generation needed for the growing population of the earth can result in scarcity of resources. Most of the mankind's vast global needs are being energized by petroleum and other natural resources. The Organization for Economic Co-operation and Development (OECD) identified that energy system in the present situation is well dependent on fossil fuels [3]. The need for research and development of alternate technologies that could help in potential reduction of fossil fuel or energy usage is being accelerated by the fossil fuel resource scarcity. In the absence of effective natural resource management with the help of potential technology advancement, economic growth can be greatly affected in the long run. Not only economic growth, over-utilization and processing of natural resources for energy needs can cause harmful emissions into the atmosphere resulting in a polluted environment.

Transportation accounts for significant amount of global petroleum consumption. As $55 \%$ of the US gasoline consumption is being consumed by the transportation sector according to the EIA [1], alternate transportation technologies can help in reducing the fossil fuel dependency. Failing to address environmental and economic concerns of fuel scarcity can affect nation's energy security and relationship between countries. Geopolitical situations can arise with a resource rich country supplying the energy demand of developing countries with fuel scarcity. Increasing scarcity of petroleum resources triggering reliance on foreign energy sources can result in rise of fuel prices. The increasing vehicle emissions from fossil fuel technologies are also accumulating harmful gases in the atmosphere adding to the existing pollution. Development of efficient and cleaner transportation technologies appear to be a promising solution to the problem of energy requirements and environmental pollution in the existing situation. Among such technologies, 
electric transmission for vehicles is observed to be a sustainable alternative with improvied efficiency, reduced emissions, and fuel costs.

\subsection{Greenhouse gas emissions}

Vehicular emissions are exhaust gases resulting due to fuel combustion in internal combustion engines. These gases are emitted into the atmosphere through the vehicle flue gas stack depending on the type of the engine. The emissions from gasoline or diesel run motor vehicles consists of hydrocarbons as volatile organic compounds (VOC), carbon monoxide, oxides of nitrogen and significant amounts of carbon dioxide gas. Gasses that entrap and emit radiant heat energy in a thermal infrared range are termed as Green House gases (GHG). The main GHGs in the atmosphere are carbon dioxide, water vapor, methane, nitrous oxide and ozone. Many human activities are resulting in increased atmospheric concentration of carbon dioxide. De-carbonization of transportation fuels and improving the efficiency of vehicle technologies are some of the routes to reduce GHG emissions.

According to the U.S. Environmental Protection Agency (EPA) 65\% of the global GHG emissions is carbon dioxide emissions from combustion of fossil fuels for electricity, transportation and heat uses. Transportation sector contributes a significant 14\% of the global GHG emissions as per 2010 statistics. Whereas the rest was contributed by electricity generation, heat production, agriculture and forestry sectors. 


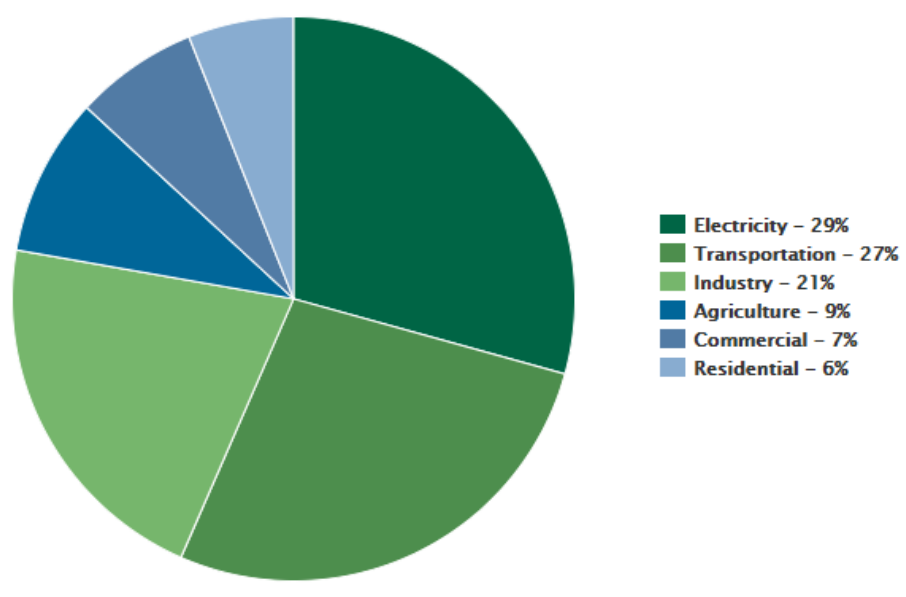

Figure 1.1. 2015 U.S. GHG Emissions by Sector [4]

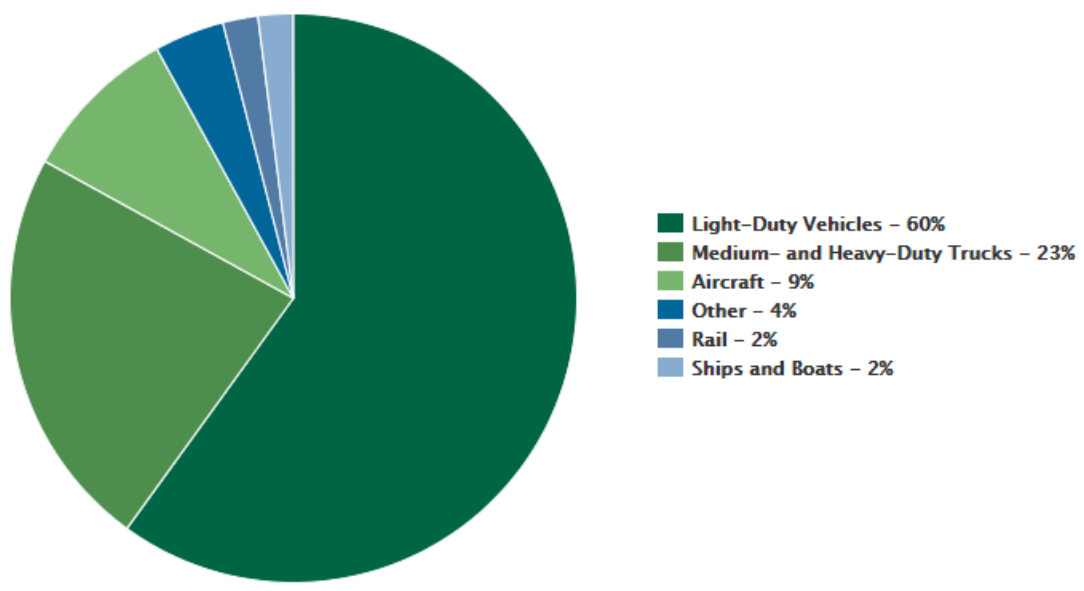

Figure 1.2. 2015 U.S. Transportation Sector GHG Emissions by Source [4]

Among all the major developed countries, United States is the second largest carbon dioxide emitter after China. The US contributes $15 \%$ of the global carbon dioxide emissions [5]. Figure 1.1 transportation sector emits $27 \%$ of the total GHG emissions in the country [4]. Passenger vehicles being the most common means of transport in this country, light duty vehicles contribute a major $60 \%$ of these emissions in 2015 [4] as shown in Figure 1.2. 


\subsection{Plug-in electric Vehicles}

Electric Vehicles (EVs) are the vehicles that run on one or more electric motors for propulsion. As the scope of this research is confined to plug-in charging type EVs, Battery Electric Vehicles (BEVs) and Plug-in Hybrid Electric Vehicles (PHEVs) that come under Plug-in type EVs are considered for this work.

\subsubsection{Battery Electric Vehicle (BEV)}

A Battery Electric Vehicle (BEV) or an all-electric vehicle stores electrical energy with the help of batteries. These batteries will be convert the chemical energy stored in them to supply the electrical energy to run the motors for propulsion as shown in Figure 1.3. They are usually recharged using grid electricity from either a charging station or a home wall socket depending on the size of the battery and the charging port they have. BEVs can provide better driving experience when compared to conventional Internal Combustion (IC) engines with the instant torque generated by the electric motors.

Technologies like idle-off and regenerative braking can minimize the battery energy consumption involved in daily transportation. Idle - off turns the ignition off when the vehicle is idling whereas regenerative braking technology enables charging of the battery while applying brakes. Battery electric vehicles does not need gasoline or diesel combustion for propulsion of the vehicle like conventional vehicles. So, there will not be any emissions associated with the propulsion of the vehicle. Hence, they are considered to be Zero Emission Vehicles (ZEVs). 


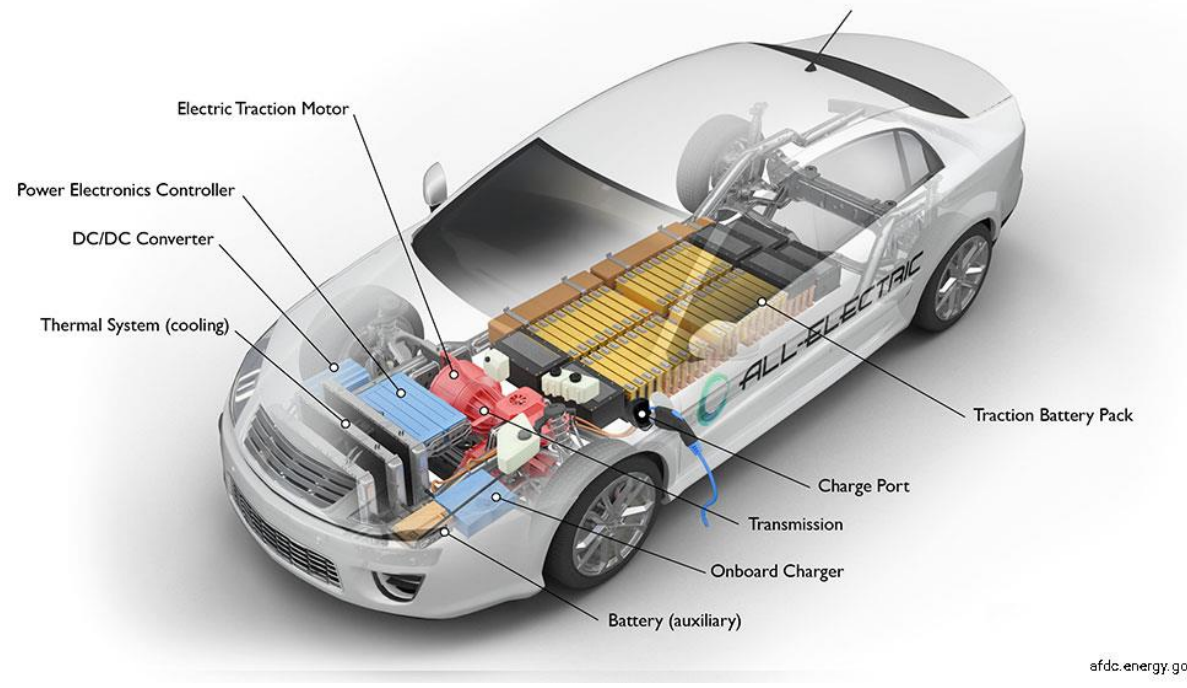

Figure 1.3.Components of a BEV [6]

\subsubsection{Plug-in Hybrid Electric Vehicle (PHEV)}

A Hybrid Electric Vehicle (HEV) has a hybrid vehicle drivetrain combining electric propulsion with conventional IC engines. They will be having an IC engine running on gasoline or diesel as a main source for propulsion and to produce electrical energy required to run an electric motor to complement engine propulsion. The US Environmental Protection Agency (EPA) states that a HEV can have fuel economy improved by more than $50 \%$ and a substantial carbon dioxide reduction potential when compared to conventional vehicles. The Plug-in Hybrid Electric Vehicle (PHEV) is a HEV with electric motor supplied by energy storage as a main source of propulsion as shown in Figure 1.4.

It is supported by an IC engine to reduce the electrical energy consumption and extend the driving range of a PHEV. So, a PHEV battery can be charged either by plugging into a source of electricity or from excess engine power. Although PHEVs involve more lifecycle emissions than that of BEVs, their oil consumption and greenhouse gas (GHG) emissions are lesser when compared to 
conventional vehicles. So, PHEV could be an alternative in decarbonization of transport energy consumption.

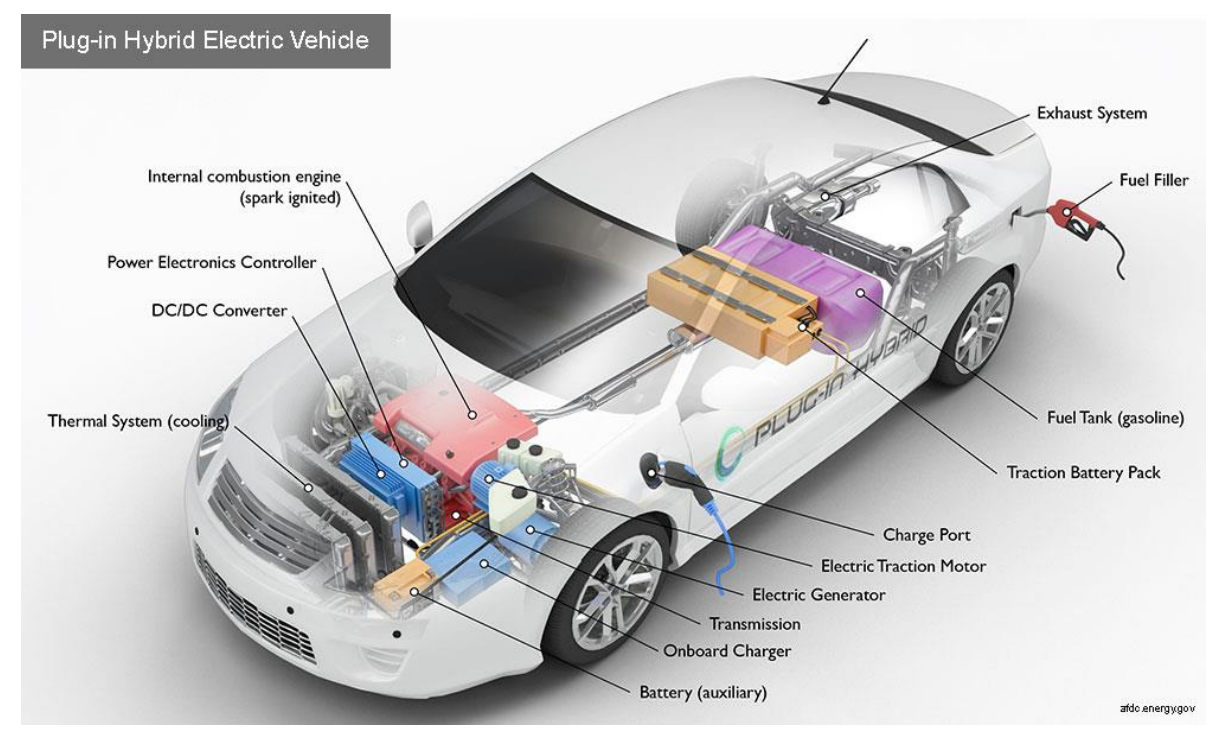

Figure 1.4. Components of a PHEV [6]

\subsection{Charging Infrastructure for Plug-in Type EVs}

Charging infrastructure or Electric Vehicle Supply Equipment (EVSE) is classified into three basic types based on electric charging rate of the EV batteries. The charging rate varies with different types of charging infrastructure due to differences in operating voltage and type of the electric current employed. Different types of charging equipment and their operating characteristics as per international standards stated by Falvo, et al. [7] are mentioned below.

\subsubsection{AC Level 1 Charging}

This equipment provides Alternating Current with a low 120 Volts (V) supply for EV charging. This type of EVSE is suitable for EVs with smaller battery capacities and low driving ranges. All plug - in EVs come with this equipment which is a simple cord set having a standard National Electrical Manufacturers Association (NEMA) connector on one side and a Society of Automotive 
Engineers (SAE) J1772 port on the other. This EVSE does not need a special power service at higher voltages and is typically used for charging EVs at home with a $120 \mathrm{~V}$ power outlet for longer durations at a slow charging rate.

\subsubsection{AC Level 2 Charging}

This EVSE will provide AC current at $240 \mathrm{~V}$ supply for residential charging or at $208 \mathrm{~V}$ supply for commercial charging applications. This equipment can charge an EV overnight, quicker than a level 1 charger. At the quickest charging rate, this equipment draws a maximum of 80 Amperes (Amps) operating at 19.2 kilowatts $(\mathrm{kW})$. A lot of residential Level 2 EVSE operate at $7.2 \mathrm{~kW}$ drawing a maximum of 30 Amps. AC Level 2 charger needs a 240 V service and a 40 Amps circuit for its operation. Most of the public charging facilities have AC Level 2 chargers and they use the SAE J1772 charging port same as AC Level 1 chargers. EVs manufactured by Tesla®work with a different port other than SAE J1772 port.

\subsubsection{Fast Charging}

This EVSE is a fast charging Direct Current (DC) supply at 208 or $480 \mathrm{~V}$ three phase service. This can be seen in public and commercial charging stations and can swiftly charge an EV when compared to Ac Level1 and Level 2 chargers. They use different charging ports like J1772 combo port, CHAdeMO port or a Tesla ${ }^{\circledR}$ combo port depending on the EV manufacturer. This EVSE

charging ports has two bottom connector pins facilitating DC fast charging. Research and development to bring the DC fast charging costs down is in place to make them accessible to all the EV owners. It takes less than two hours to completely charge a typical EV.

\subsection{Electrical Load / Demand billing - Importance}

Along with energy charges, demand charges are a part of any electricity bill. The electric utility providers bill the facilities for the electrical load supply based on the electric peak demand. 
Electrical peak demand is established when the utilization of the resources i.e. charging stations in our case, is maximum. Different types of facilities are billed on various rate schedules by the utility provider. It is a good measure to check for the appropriate rate schedule to reduce the electricity charges for individual cases. Some states in the country have high charges associated with electrical demand. In California, Rolling peaks established for continuous fifteen minute intervals are recorded in $\mathrm{kW}$ and the maximum of these peaks for each individual month is considered to be the monthly peak demand on which the facilities get billed.

An unnoticed peak demand established for a 15 min interval can result in whole month's utilization at lower demand being charged at higher peak established once or more in that month. Considering the abundant charges, it is a very important practice to monitor the demand for not allowing a continuous peak demand in the consumption. A facility with multiple charging stations will have a maximum electrical demand when most or all the charging stations are occupied and charging. Electrical demand analysis and understanding is a suggested measure for any facility installing electrical charging stations. Understanding electrical consumption charges, demand charges and EVSE regular maintenance charges can help evaluating the financial feasibility of establishing EV charging stations.

\subsection{The Plug-In Electric Vehicle (PEV) Market - Need for EVSE Establishment}

With accumulating environmental concerns, the number of people adapting EVs as their means of transport increased too. Increasing PEVs also appear to be a cleaner, efficient and economical alternative for fuel driven vehicles. According to Argonne National Laboratory (ANL) [8], 19,396 plug-in vehicles (9,589 BEVs and 9,807 PHEVs) were sold throughout April 2018 in the US, up 46.0\% over the sales in April 2017. These recent PEV sales numbers clearly depicts their rising trend in a very small period. ANL's monthly trends by models (Figure 1.5) over the past years are 
depicting a promising continuous rise in PEV sales. In these circumstances, lack of charging stations appears to be a predominant problem for the gathering PEVs on long duration road trips. National Renewable Energy laboratory evaluated the requirement of non-residential charging infrastructure within public facilities like communities and Interstate corridors. Their research portrayed a strong correlation between PEV and EVSE sales. Prioritizing EVSE establishment based on driving patterns and vehicle characteristics can optimize the usage and economics involved.

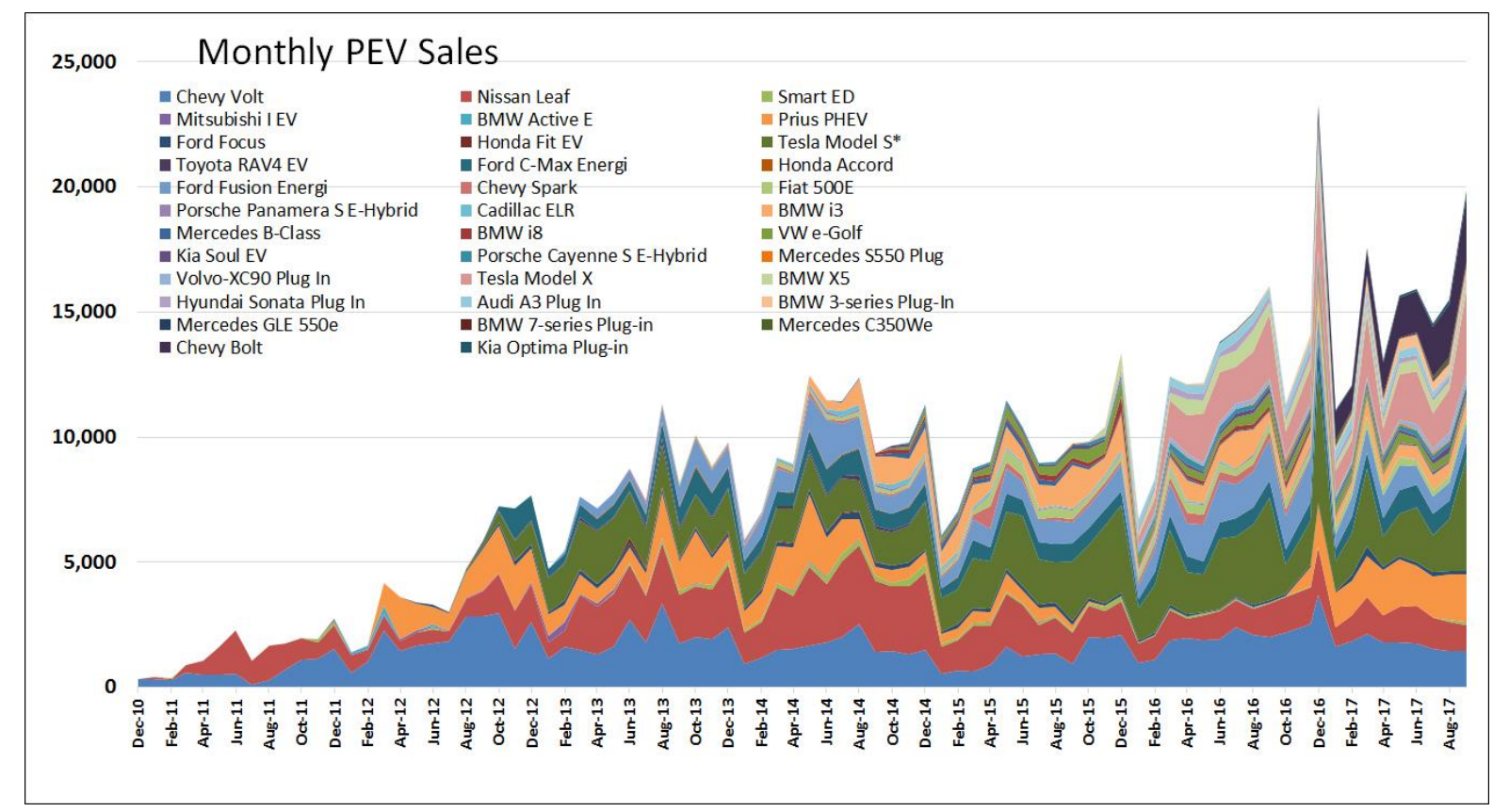

Figure 1.5. US PEV Sales by Model [8]

\subsection{Electric Vehicle Battery Life and Reuse}

Another important concern in EV lifecycle is life of the EV battery. Storage capacity can be degraded over time and the battery needs to be replaced. This battery life can be affected by problems like high operating temperatures and rapid discharge on usage. The EV battery service life may end when it loses most of its storage capacity resulting in significant driving range loss with battery degradation. The lifespan of EV batteries could range from 4 to 14 years. With the 
increasing number of EVs on road, significant amount of degraded battery waste gets accumulated too.

Although usage of EVs in an eco-friendly alternative, the increasing degraded battery disposals can affect the atmosphere and is a growing environmental concern. These batteries are manufactured using lithium, cobalt, manganese, nickel, and graphite and other rare metals as primary components. EV batteries can contain electrolytes, metals, rare earth elements, and toxic materials. These materials can be a potential risk to human health and can adversely affect the environment. Improper disposition of these wastes can be a fire or shock hazard. These degraded batteries can be reused after retaining maximum fraction of their original storage capacity at lower costs. These retained batteries can be used as cheaper energy storage options for alternate purposes like stationary energy storage systems of various scales, such as residence, commercial facility, or power grid.

\subsection{Need for Research}

The rising petroleum derivatives' prices and environmental pollution associated have augmented the development of environment friendly Electric Vehicles (EVs) and their establishment in transport system. Transportation sector being a major energy consumer, leaning towards more energy efficient EVs will have significant impact in reducing petroleum dependence and improving transportation sustainability. Concerns about environmental pollution are increasing day by day over the recent years. Majority of the public facilities and parks' visitors adapting a 'go green' perspective, share similar concerns. According to International Energy Agency (IEA), the number of EVs deployed into the automobile market around the globe in the period 2010-16 has increased rapidly. In this scenario, lack of adequate charging infrastructure is a prevailing problem for the EV drivers everywhere. Extending the charging infrastructure or Electric Vehicle Supply 
Equipment (EVSE) in public facilities can be an initial step towards solving the above problem. This research focuses on operational charges involved in establishing EV charging stations are to be analyzed to decide on economic feasibility.

\subsection{Objectives}

This research focused on forecasting the arrival traffic density and charging pattern of Plug-in Electric Vehicles (PEVs) based on pertinent factors across various seasons and holidays over a year. Demand analysis of the considered public facility based on electrical supply requirements over different times of the year is to be performed to curtail demand and save on demand charges. The simulated data has to be observed to make a decision on the optimal number of charging stations to be established in a public facility which are sustainable and economically viable. The objectives of this research are:

- To develop Monte Carlo simulation of a scenario depicting traffic arrival patterns using various pre-recorded and categorical data and based on following factors.

1. Weather Severity

2. Time of the year

- To develop a discrete event simulation modelling the charging patterns of the EV arrivals.

- To estimate Electrical energy consumption, Demand and costs based on the car arrival patterns over a year for the above simulated data.

- To perform a sensitivity analysis of electrical demand and supply costs with varying weather severity and number of charging stations.

\subsection{Conclusion}

This chapter helps in attainment of a detailed understanding of the existing transportation scenario and its energy consumption globally and in the US. In the later sections, problems with the existing 
energy systems and their impacts on the environment due to their GHG emissions were discussed. Different EVs considered in the study, their components and different EVSE available in the market were introduced in this chapter. Finally the objectives of this research are stated. 


\section{Literature Review}

\subsection{Introduction}

Over the past few decades, transportation sector is contributing a major portion of global greenhouse gas (GHG) emissions that entraps heat making the globe warmer. The United States (US) Environmental Protection Agency (EPA) tracked that approximately $28.5 \%$ of the 2016 U.S. greenhouse gas emissions associated with different human activities is from transportation sector, involving combustion of fossil fuels. A significant $60 \%$ of these US transportation sector's GHG emissions are from light duty vehicles fleet which is the most common means of transportation in US [4]. The International Energy Agency (IEA) believes that de-carbonization of energy sector by electrification can be a pathway to lower emissions. Transport electrification supporting cleaner energy sources and greater efficiencies can help in achieving de-carbonization of energy sector to a great extent.

Influence on hybrid EV purchase and use by denotations and connotations of typical customers were observed by Heffner, et al. in their study [9]. The data was collected by conducting semi structured ethnographic interviews in detail for about two hours each with 25 hybrid EV owning households living in California, US. The large scale data collected in this study are statistically modelled employing Semiotic theory methods. Qualitative analysis of the collected data was performed considering the assumptions of the rational actor model from economics. This study depicts the increasing concerns to preserve the environment and their influence on EV purchases and use. Public parks may have visitors with environmental, and social values. Public parks are one of the best recreation choices for the people with bio centric environmental ideals. Also nine

of every ten lengthy trips in US are preferably using personal vehicles according to Bureau of 
Transportation statistics [10]. Increasing environmentally concerned visitor arrivals to public parks with EVs substantiates both the above discussed surveys.

Substantial emissions are involved in different vehicle production, distribution, utilization, and disposal processes in their life-cycle. Emissions from EV battery disposal can be reduced considerably by extending the existing recycling and reusing procedures. EVs powered by electricity has significant emissions involved with electricity production using different fuels depending on their geographical location and resources' availability. But, EVs in a sense help releasing lesser tailpipe emissions than regular fuel run vehicles. Unlike fuel run vehicles, full electric vehicles with battery run powertrain has zero tailpipe emissions. EVs with zero tail pipe emissions are termed as Zero Emission vehicles (ZEVs). In 2012, California state government issued an executive plan to support the ZEV market in the state by calling for 1.5 million ZEVs by 2025. The state increased the ZEV adaption with the help of the California Zero Emission Vehicle Regulation. Clean Air Act allowed states Connecticut, Maine, Maryland, Massachusetts, New Jersey, New York, Oregon, Rhode Island and Vermont to follow California ZEV regulations to increase ZEV sales. All these steps towards sustainability results in escalation of the number of EVs not only in the country, but also round the globe.

\subsection{Lack of adequate Charging Infrastructure as a Prevailing Problem}

With this escalation in EVs on road, and considering the limited driving range of even the recent EV designs, lack of adequate charging infrastructure is a major barrier for the adaption of EVs. In 2012, Ona Egbue and Suzanna Long [11] worked together in analyzing potential EV customers' knowledge, interests, attitude and perceptions to observe different factors that are restricting the adoption of EVs to find out if their acquirement decision is influenced by sustainability matters. They developed an internet based survey program to collect interests and opinions of EV owner 
sample population covering students and employees of a university. To broaden the scope of their research, they extended the sample population to technology enthusiasts and EV owners having expertize in diverse areas like science, technology, and engineering. In different sections of the survey, socio-economic details, perceptions, attitudes, environmental and sustainability concerns of the respondents in detail were enquired and statistical analysis of the responses was done. This work employed a Chi-squared test for analyzing the responses from around 500 respondents to explore the differences in each of their concerns and ideas. Evaluation of these numerous responses from their study, they identified that lack of adequate charging infrastructure is bigger barrier for more number of people adapting EVs along with limited battery range and cost parameters.

\subsection{Public Charging Infrastructure as a stopgap}

Research and development of different EV technologies to improve powertrain efficiency, battery size and selection, vehicle design, charging systems and direct current (DC) fast charging etc. are in place to support the EV adaption. In the present situation, expenditure in improving or extending the existing charging infrastructure appears to be insufficient. In an analysis of geographical distribution of EVSE, IEA observed a positive relationship between public charging infrastructure and global EV adaption. Identifying this urgent need to finance for charging infrastructure and escalate EV adaption, state and federal governments research was done to improve electric vehicle technologies. To measure gains of extending the deployment of publicly available charging infrastructure Wood et al. [12] at the National Renewable Energy Laboratory (NREL) used advanced simulation tools. For this, NREL developed the Battery Lifetime Analysis and Simulation Tool for Vehicles (BLAST-V) with the support of U.S. Department of Energy's Vehicle Technologies Office (VTO). In their research, they discussed the spatial capabilities of Level 2 EVSE in Seattle, Washington area and evaluated the incremental utilization by observing 
different real time and simulated EVSE usage scenarios. In this process, travel profiles, driver behavior, vehicle performance, battery attributes, environmental conditions, and charging infrastructure were considered as simulation parameters for detailed understanding and analysis. As a part of their work, it was observed that $15 \%$ of all charge events are happening in locations away from home elucidating the need of more public charging infrastructure.

To meet this, government is encouraging various public and private organizations to deploy EV charging corridors in multiple number at public facilities. The US Department of Transportation (DOT) developed an action plan for establishment of several national EV charging corridors covering more than 40 states in the country. Similarly state governments, vehicle manufacturers and utilities are also committing programs to accelerate the deployment of EV charging infrastructure in those corridors. Along with all these government measures that are encouraging establishment of EV charging stations in public facilities, incentive programs for EV owners have their own impact on EV adaption. Rebates to support EV charging infrastructure investment and installations are also available to encourage public facilities.

\subsection{Role of Public incentives in EV adaption}

Considering the environmental conditions and the need for EV adaption, different researchers have explored multiple options encouraging EV adaption. Sierzchula, et al. explored the impact of financial incentives and other social, economic and demographic factors on the EV adaption and sales in their study [13]. EV adaption and charging infrastructure data regarding Battery Electric Vehicles (BEVs) and Plug-in Hybrid Electric Vehicles (PHEVs) in 30 countries is collected. As a part of it, different variables including federal financial incentives, $2012 \mathrm{EV}$ market share, EVSE per capita, fuel and electricity costs, education, income, urban density and environmentalism indicator (EI) data were statistically analyzed. With the help of regression analysis, significant 
correlation is observed between BEV, PHEV sales and federal incentive programs, EVSE availability, ample existence of EVSE production and support facilities around the area. The results from this work clearly support the influence of enough charging infrastructure availability on EV adaption in a country. They also discovered that the BEV and PHEV market share did not have significant dependence on different socio-economic variables. This study have not considered the EVSE density in particular, instead a homogeneous distribution of charging station scenario was assumed while collecting the charging infrastructure data. Narassimhan and Johnson (2014) presented a macroeconomic analysis [14] of policy incentives, charging station density and HOV exemption in place effects on PHEV and BEV registrations per capita for eligible driver population. Different demographic variables' like median household income, residential energy consumption per capita, age, and percentage of graduates' data was collected and regression analysis is performed separately for both types of EVs. Database from Alternative Fuels Data Center (AFDC) laws and incentives to boost EV market and registration data from 2008 to 2014 through the first quarter are analyzed as a part of this study. In addition to the above mentioned variables the effect of gasoline price increase is also considered in the study. This work concluded that PHEV market is being more influenced by non-monetary incentives like HOV exemptions than by state monetary incentives like tax credits, rebates etc. It also concludes that the EV charging infrastructure availability greatly impacts both BEV and PHEV purchases and extension of EVSE can reduce the EV limited range concerns and lift EV market.

Along with federal incentives, most of the states in the US are offering decent incentives too. Maryland Energy Administration has an EVSE rebate program [15] through which government, businesses organizations and residents can acquire rebates for purchase and installation of EVSE. In addition to this program they provide EV incentives in the form of Federal income tax credits, 
Maryland excise tax credit and HOV lane utilization to encourage EVs on their roads. Most other states have similar incentive programs and National Conference of State Legislature (NCSL) has a database of all the available incentives in the country in their website.

\subsection{Different Models forecasting EV arrival And Charging Patterns}

To obtain a stochastic storage capacity needed for an EV parking lot, Guner et al. modelled the arrival and departure patterns of EVs in their work [16] . Modelling is done by Monte Carlo simulation using different stochastic and deterministic variables. Using statistical data from a parking lot in Istanbul, Turkey that can accommodate 500 vehicles, each car arrival and departure time data is generated and a kernel density estimation of probability distribution for the car parking duration variable is performed. The simulated data on analysis results the fraction or percentage of available storage at different times of the day.

Xi et al. [17] developed a simulation model to determine optimal location for maximum utilization of level 1 and level $2 \mathrm{EV}$ chargers in central-Ohio region. The model employs a linear function of different socio-economic and demographic variables to estimate EV acquiring probabilities in the fixed sub regions. Sensitivity analyses are performed to understand the effect on EV charger location by different vehicle charging decisions. The model helps in optimizing location of slow chargers in the considered region and the sensitivity analyses predicted that slow chargers are on the economical side compared to fast direct current chargers. This model is limited due to a fixed consideration of study region, EV driving range and efficiency measured in electrical energy per each mile in the simulation.

Cao et al. designed an optimization method to curtail the EV charging electrical loads based on the time of use charges associated. In this research [18], the involved charging costs were defined as a function of charging power of an EV battery and its state of charge. A model minimizing these 
charging costs was developed to simulate an optimal charging pattern. Comparison of the electrical demand at time intervals and final charging costs has been done between model generated optimized charging pattern and representative charging pattern. They showed that the optimized charging pattern created by their model resulted in lesser loads and hence the costs when compared to a typical pattern.

A dynamic rolling optimization approach [19] for personal PHEV owners has been developed by Kong et al. that helps in deciding an ideal time schedule to charge. This approach was driven by two considerations, fluctuation in electricity costs with time slots in a day and varying driving routines. A driving model to statistically analyze the energy demands based on historical driving records of PHEV owners was made using an algorithm developed employing heuristics. An extensive driving data of 1047 PHEV owners' driving records for 246 representative days was collected and analyzed in their work.

To decide on a finest network of EV charging stations for a community, Faridimehr et al. [20] developed a two stage stochastic programming model. The research focused on the variations in EV battery state of charge, arrival times, charging times, type of vehicles, driving range associated, demand during weekends and weekdays, charging preferences of an EV driver and EV adaption rate in the community. They collected data performing sample average approximation surveys regarding different variations mentioned on a sample of scenarios. This vast data set is analyzed quickly for an optimal solution employing heuristics that involved a scoring measure. Optimal solution generated is evaluated using computational experimentation using various public data services.

Alizadeh et al. [21] proposed a stochastic model to forecast the electrical demand involved in charging activity of EVs to help in demand response management using actual metered data and 
varying demand prices. As a part of the forecast, the electrical load is modeled analyzing the random EV arrival employing queuing theory. The model simulates the random arrivals using a non - homogenous Poisson distribution and a cumulative distribution function based on required charge for charging times. The model developed is capable of taking historical data as input to forecast the EV charging demand.

\subsection{Conclusion}

In this chapter, literature regarding the existing EV situation and the problem involved is discussed in detail in the initial paragraphs. Lack of adequate charging infrastructure is established as a prevailing problem and how public charging infrastructure deployment can be a stopgap for the problem is elucidated with the help of existing literature. Federal and State governments' actions for encouraging the establishment of public EVSE are mentioned in the later sections. Also the role played by the public incentives in increasing the EV adaption is discussed using existing literature. Wide research forecasting the arrival and charging patterns of EVs and their approaches are discussed to explain and distinguish their methodologies. 


\section{Methodology}

\subsection{Problem Statement}

Substantial research and development was done to improve electric vehicle technologies in different areas like battery selection, electric motors, vehicle design, transmission systems and direct current (DC) fast charging etc. Various implementation and operational charges involved in establishing EV charging stations are to be analyzed to decide on economic feasibility. Considering the requirement of EV charging stations, there is a need for more research in the direction of economic feasibility and costs involved. The objective of this research is to develop a decision support system that helps and enables facilities or organizations to analyze the cost implications of installing and operating the Electric Vehicle Supply Equipment (EVSE). As a part of it, to forecast the public facilities' EV arrival traffic density and charges associated, a Monte Carlo Simulation has been developed. The EV traffic arrival patterns to a public facility with multiple charging stations considering weather severity and time of the year can be generated. This can be done using a spreadsheet model developed using Visual Basic for Applications ${ }^{\circledR}$ (VBA). A scenario depicting the charging patterns of the EVs arrived to that public facility can be dynamically simulated using a discrete event simulation model developed using Arena ${ }^{\circledR}$ simulation software based on the generated arrival pattern. A detailed energy cost based sensitivity analysis mainly with electrical demand and charges associated with electricity consumption can be done using this data for the simulated scenario.

\subsection{Approach}

The simulation required for this research is performed in two parts due to the complexity and programming challenges involved in the work. Each simulation run depicts the EV arrival and 
charging patterns for a year. The first half which is the generation of EV arrival pattern to a public facility decided by the following factors.

i) Probability of weather severity in the geographical area of the facility considered and

ii) Busy days of a public facility which includes United States (US) list of holidays, weekends, spring-break, Thanks-giving week and the summer months.

The second half of the work is simulating the charging pattern of the arrived EVs based on the arrival pattern generated before. This simulation can depict the complex logistics problem involved in the charging process. It is capable of representing a visual in which EVs arrive to the charging stations, decide to get charged or leave if all the available stations are occupied for given significant amount of time and get processed according to the decision made. Simulated data of different process variables involved in the simulation run is then used to estimate electrical energy consumption, demand charges and perform detailed sensitivity analysis This simulation is done using a VBA based spreadsheet model and Arena ${ }^{\circledR}$ simulation software, discussed below.

\subsection{Methods and Software Tools}

This research involves a Monte Carlo Simulation of EV arrival and charging patterns at a public facility based on a heuristic approach and estimate the operational charges resulting. The EV arrival pattern spreadsheet model is generated using Visual Basic for Applications $®$ in Microsoft Excel®. Whereas the discrete event simulation of the charging pattern based on the arrivals is visualized using Arena® Simulation Software.

\subsubsection{Heuristic Approach}

Heuristics are flexible techniques that are employed to solve a complex problem. So, a heuristic approach can be defined as a technical approach in problem solving, learning or discovery employing a practical method developed on general understanding which can give an approximate 
and immediate solution but may not be optimal. It is a decision making approach in which procedural decisions are made based on general understanding. It is employed when classic methods take longer durations and fail to give exact solutions. A number of understanding and learning researches in science and technology employ heuristic approach to define strategies [22].

\subsubsection{Monte Carlo Simulation}

Monte Carlo Simulation is modeling the probability of different results in a procedure, mathematical or a statistical model that cannot be simply estimated because of the involvement of random variables using different set of random numbers as sampling data. This method involves calculation of several outcomes of different variables involved in the method with multiple sets of input values generated with randomness based on a probability distribution or its function. This method is extensively used in development of statistical methods, modification and comparison of methods.

Monte Carlo Simulation is capable to show the changes in set of outcomes of variables or an equation with variables that undergo discrete events. A Monte Carlo Simulation which progresses some amount of time after one event is executed is called as an event driven Monte Carlo Simulation. Whereas one which processes discrete events involved in a method in fixed given time interval is called as a time driven Monte Carlo Simulation. They can be differentiated based on how the modelled values are tracked as the simulation progresses.

Indirectly, it performs risk analysis by modelling probable results by substituting different sets of random values generated using probability distributions, in the equation or method involving variables. Further, it calculates outcomes over and over each time using different patterns of input 
values. Based on number of uncertainties involved, simulation requires hundreds and thousands of recalculations to be done before generating results.

\subsubsection{Visual Basic for Applications®}

Visual Basic for Applications ${ }^{\circledR}$ (VBA) is a programming language that allows automation and customization of detailed computer processes and calculations. VBA being a potential feature in Microsoft Excel®, allows users to create user-defined functions, access Windows APIs and use dynamic-link libraries (DLLs) and customize the application. VBA is the tool enabling people to code programs they require to control Excel®. It has several pre-defined functions and has the ability to call the functions in the application it is being used for. These features help the user in automating a time consuming program or process the data has to undergo with just a simple click. This can be done either by using macros simply or by writing a code to program data, the way user wants.

\subsection{4. $\underline{\text { Arena }}{ }^{\circledR}$ simulation software}

Arena ${ }^{\circledR}$ Simulation Software is a potential tool that helps the user predict, evaluate and validate system or process strategies for effective and optimized performance. Discrete event modelling that can optimize complex processes can be done without much effort using Arena ${ }^{\circledR}$ software. It follows a flowchart modelling method with multiple process variables defined as per several predefined or user-defined functions or statistical distributions.

This software can represent the actions of a complex system as a set of well-defined and ordered events virtually in any variable process with limited resources involving complicated interactions. Its ability to two dimensionally or three dimensionally visualize the simulation run of the whole process is of great help in demonstrating the simulation. This software can process multiple 
variables for the certain period of time, for multiple replications. Different statistical analyses can be done and detailed reports can be generated with all the results.

\subsection{Assumptions}

1. The charging times of EV in the simulation model are assumed to be following a Triangular distribution.

2. It is assumed that only one EV will be waiting to get charged when all the charging stations are occupied and the next EV arrived will leave the facility without charging.

3. It is assumed that the days before and after the Spring break, Thanks giving break and the US list of holidays will be having maximum EV arrivals to the public facility.

4. EV arrivals were modelled assuming that minimum number of EVs arrive to charge, in severe weather conditions even on a busy day for a public facility.

5. The EV arrival density to the facility is assumed to be uniform at different times of the day.

6. The study considers multiple arrivals of the same EV as different EV arrivals.

7. The effects of vehicle's climate control system on EV energy consumption in different seasons are not considered in this study.

\subsection{Electric Vehicle arrival pattern spreadsheet model}

The EV arrival pattern spreadsheet model is a user friendly model which enables the user to generate EVs arrival to a public facility. The VBA code for the whole arrival pattern spreadsheet model is attached in appendix at the end.

\subsubsection{Capability}

This model is intended to generate random EV arrivals for each separate simulation run. This spreadsheet model gives the number of EVs arrived to a public facility on each day in a 365 day calendar year. The number of EVs for a year is given in individual cells for 365 rows in a column 
of the spreadsheet. Based on the simulated number of EVs arrived on each day for a year, the model divides them into number of Tesla ${ }^{\circledR}$ model EVs and regular EVs arrived in a year taking user's input. Random arrival times based on these number of different types of EVs for each day in a calendar year can be generated by this model.

\subsubsection{Factors Considered}

The number of EVs arrived on each day to the public facility can be influenced by different factors such as weather effect on visitor arrivals, visitor arrivals at different times of the year, population density and places of interest in public facility's location etc., in several ways. The first two factors among the mentioned influencing factors has a direct impact on visitor arrivals to a public facility. Whereas the latter two factors are dependent on the demographics of the considered public facility's location and needs environmental monitoring using Geographic Information Systems (GIS). Although, they have a partial influence over the visitor arrivals to a public facility, due to the complexities involved in quantifying accurately the model is developed based on two factors. The two important factors considered by this simulation model that influence the visitor arrivals to a public facility are:

\subsubsection{Weather Severity}

Seasonal Weather has a pronounced influence on the visitor arrivals to a public facility. So, the EV arrivals to the public facility will be depended on weather severity on the day of a year. Hence, probability of weather severity in the geographical location of the facility considered is taken into account in generation of the number of EVs with the severe weather data from National Oceanic and Atmospheric Administration (NOAA) [23]. This NOAA data for a particular region represents weather behavior and changing patterns in that area. In this model, two levels of weather severity represented as Weather Factors (WF) are considered as shown in Table 3.1 below. 
Table 3.1: Weather Severity Levels

\begin{tabular}{|c|c|}
\hline Severity Level & Weather Factors (WF) \\
\hline Comfortable Weather & 1 \\
\hline Severe Weather & 0 \\
\hline
\end{tabular}

\subsubsection{Time of the year}

Public facility visitor arrivals are dependent on day of the week and school vacations in particular times of the year [24]. So, the busy days of a public facility includes United States (US) list of holidays, weekends, spring-break, Thanks-giving week and the summer months. It is considered that all the above mentioned times of the year have more arrivals compared to the rest of the days in a year. The model represents all the holidays mentioned above with Holiday Factor (HF) as ' 1 ' in the spreadsheet model generated. Rest of the days are represented with HF as ' 0 ' in the model indicating less number of visitor arrivals on different days of a year to the public facility. As our research is focused on a public facility in US, the list of US calendar holidays as shown in Table 3.2 below are considered.

Table 3.2: List of US Holidays

\begin{tabular}{|c|c|}
\hline Holiday & Date \\
\hline New Year Day & 1-Jan \\
\hline Martin Luther King Jr. Day & 16-Jan \\
\hline President Day & 20-Feb \\
\hline Memorial Day & 28-May \\
\hline Independence Day & 4-Jul \\
\hline Labor Day & 3-Sep \\
\hline Columbus Day & 8-Oct \\
\hline Veterans Day & 11-Nov \\
\hline
\end{tabular}




\begin{tabular}{|l|l|}
\hline Christmas Day & 25-Dec \\
\hline
\end{tabular}

\subsubsection{Inputs}

The model generates different number of EVs for each day of a year based on multiple input values from the user operating the model. The two important inputs the user needs to provide the model are the minimum and maximum number of EV arrival data. First, the model requests the user to enter minimum number of EVs arriving per day in an input box as a dialogue. This should be an integer value from ' 0 ' to ' 30,000 '. After entering the value in the first input box, the model similarly requests for an integer value in the second input box asking for maximum number of EVs arriving per day as a dialogue.

The model also requests the user to provide a fraction of Tesla ${ }^{\circledR}$ EVs among the total EVs arriving round the year to their public facility after entering the maximum arrivals as another input box. The value entered in this input box will be used as a probability in the model to generate random number of Tesla ${ }^{\circledR}$ EVs. The fraction entered can be observed in the form of number of Tesla $®$ EVs arrived to that public facility in a year among the total number of EVs arrived in a year. All these three inputs given at the beginning of the model before the simulation are displayed in the first spreadsheet (Arrival Pattern).

\subsubsection{Model Outcomes}

The model generates three different levels of arrivals randomly based on the weather severity in the geographical location of the facility and time of the year. The first level of outcome is number of EVs arriving per day will be equal to the minimum number of EV arrivals per day to that facility. The outcome number of EVs will be minimum in two cases when the weather factor is ' 0 ' and holiday factor is either ' 0 ' or ' 1 '. This indicates that the public facility visitors and EV arrivals will 
be minimum in severe weather conditions (WF is ' 0 ') irrespective of time of the year (i.e. whether it is a holiday or not).

The second level of outcome is the number of EVs arriving per day being an average of the minimum number of $\mathrm{EV}$ arrivals per day and the maximum number of $\mathrm{EV}$ arrivals per day to that facility. This case can be represented on a day when the WF is ' 1 ' and the HF is ' 0 ', indicating a working day with comfortable weather conditions. This represents a moderately busy day at a public facility.

The third level of outcome is number of EVs arriving per day will be equal to the maximum number of EV arrivals per day to that facility. The outcome number of EVs will be maximum in the case when the weather factor is ' 1 ' and the holiday factor is ' 1 ', indicating maximum EV arrivals to that facility on a beautiful holiday. This indicates that the public facility visitors and EV arrivals will be maximum with comfortable weather conditions on holiday times of the year representing a typical busy day at a public facility. All three possible outcomes and the conditions considered are tabulated below in Table 3.3.

Table 3.3: Number of Electric Vehicles' Outcome Levels

\begin{tabular}{|c|c|c|c|c|}
\hline $\begin{array}{c}\text { Weather } \\
\text { severity }\end{array}$ & $\begin{array}{c}\text { Weather } \\
\text { Factor }\end{array}$ & $\begin{array}{c}\text { Time of the } \\
\text { Year }\end{array}$ & $\begin{array}{c}\text { Holiday } \\
\text { Factor }\end{array}$ & No. of Cars \\
\hline Severe & 0 & $\begin{array}{c}\text { Working } \\
\text { Day }\end{array}$ & 0 & Minimum \\
\hline Severe & 0 & Holiday & 1 & Minimum \\
\hline Comfortable & 1 & $\begin{array}{c}\text { Working } \\
\text { Day }\end{array}$ & 0 & Average of Max and Min \\
\hline Comfortable & 1 & Holiday & 1 & Maximum \\
\hline
\end{tabular}

Based on the above outcome, a set of $\mathrm{EV}$ arrivals per each day for a year in 365 rows are generated respectively. The model then simulates the number of Tesla® EV arrivals and regular EV arrivals 
using the probability of Tesla ${ }^{\circledR}$ EVs among the total EVs arriving round the year to their public facility input from the user. Further steps in the model involves simulating these EV arrival times separately for both Tesla® EVs and Regular EVs. The praiseworthy capability of this spreadsheet model developed is the generation of random arrival times for all the simulated number of EVs of both the types. The model creates two separate spreadsheets of EV arrival times, one for Tesla® EVs and the other for Regular EVs on each and every day of a 365 day simulated calendar year.

The total number of EV arrivals, individual EV arrivals of each type, percentages of total EV arrival for each type and the weather conditions are also displayed in the first spreadsheet of the model (Arrival Pattern). Whereas the arrival times are displayed in different sheets one for each type named 'Regular Numbers' and 'Tesla® Numbers'.

\subsection{Charging Pattern and Logistics Modelling Simulation}

The model is a discrete event simulation designed to replicate and visualize the charging pattern of the EVs coming to a public facility with multiple charging stations of two types. The Arena® Simulation Software mentioned in section 3.3.4 is used to generate a flowchart based model to simulate EVs as per the given input pattern and predict the charging times as shown in Figure 3.1. The simulated data generated by the Electric Vehicle arrival pattern spreadsheet model, mentioned in the previous section serves as the input for each simulation run. The model developed is capable of handling data cells as input from the spreadsheet model for the simulation.

This model simulates the charging pattern of the EVs arrived to the public facility in four sections taking care of different discrete events involved in the logistics of vehicle charging. The four sections of the simulation discussed below separately in detail are:

\section{Creating EVs as Entities}


2. Decision Making

3. Charging Process

4. Counters and Writing out Results

The simulation model developed in Arena ${ }^{\circledR}$ Simulation Software is shown in Figure 3.1 below. 


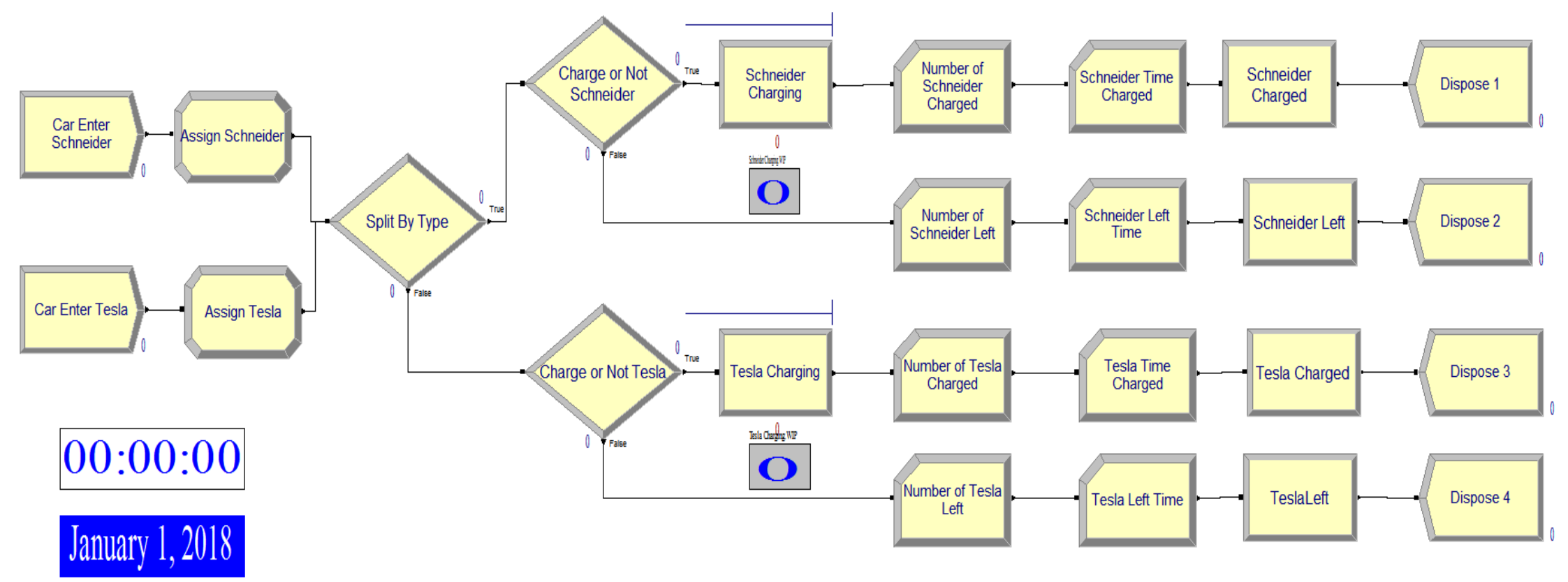

Figure 3.1. Charging Pattern and Logistics Modelling Simulation 


\subsubsection{Creating EVs as Entities}

The first section in the simulation is the creation of EVs as entities arriving into the model. This section involves generation of entities and then assigning time variables and pictures to each entity type for further processes and entity related modules. The assigned entities are then input to a module and channeled to respective processes. All the steps involved in this section are shown in Figure 3.2.

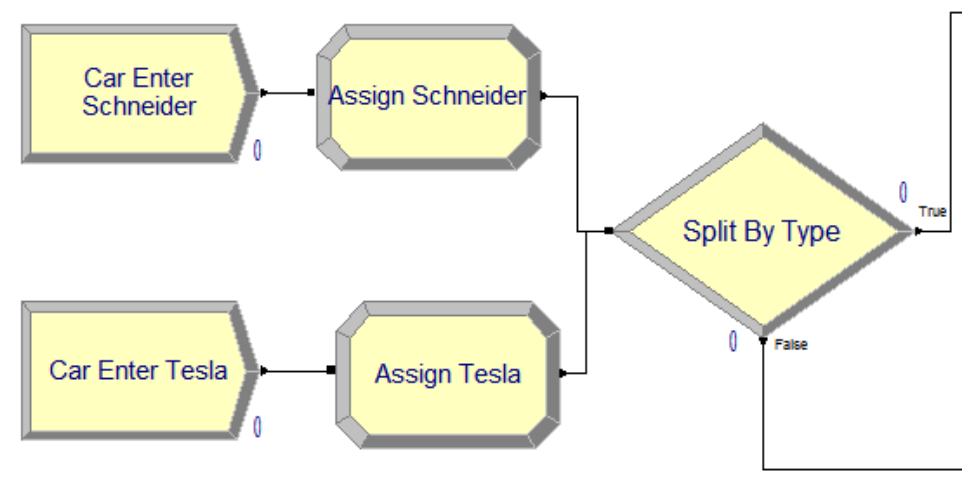

Figure 3.2. Creating EVs as Entities

The generation of entities is done using a Create module in the software which enables us to push entities into the model with certain time intervals. These time intervals can be input as random exponential values, as a pre-defined schedule, as a constant value or as an expression. In our case, schedule for Regular EVs and Tesla ${ }^{\circledR}$ EVs from EV arrival pattern spreadsheet model named as 'Schedule 1' and 'Schedule 2' respectively are given as a schedule input selected from the drop down menu in the create module as shown in Figure 3.3. This schedule is two columns of integers representing each EV arrival as ' 1 ' in one column and every hour of 8760 hours in a simulated year in the other. The 'Schedule 1' data is available from the 'Regular Numbers' spreadsheet and 'Schedule 2' data is available from the 'Tesla ${ }^{\circledR}$ Numbers' spreadsheet in the model. The entity type is also allocated in the create module as shown in Figure 3.3 for further assignments. 


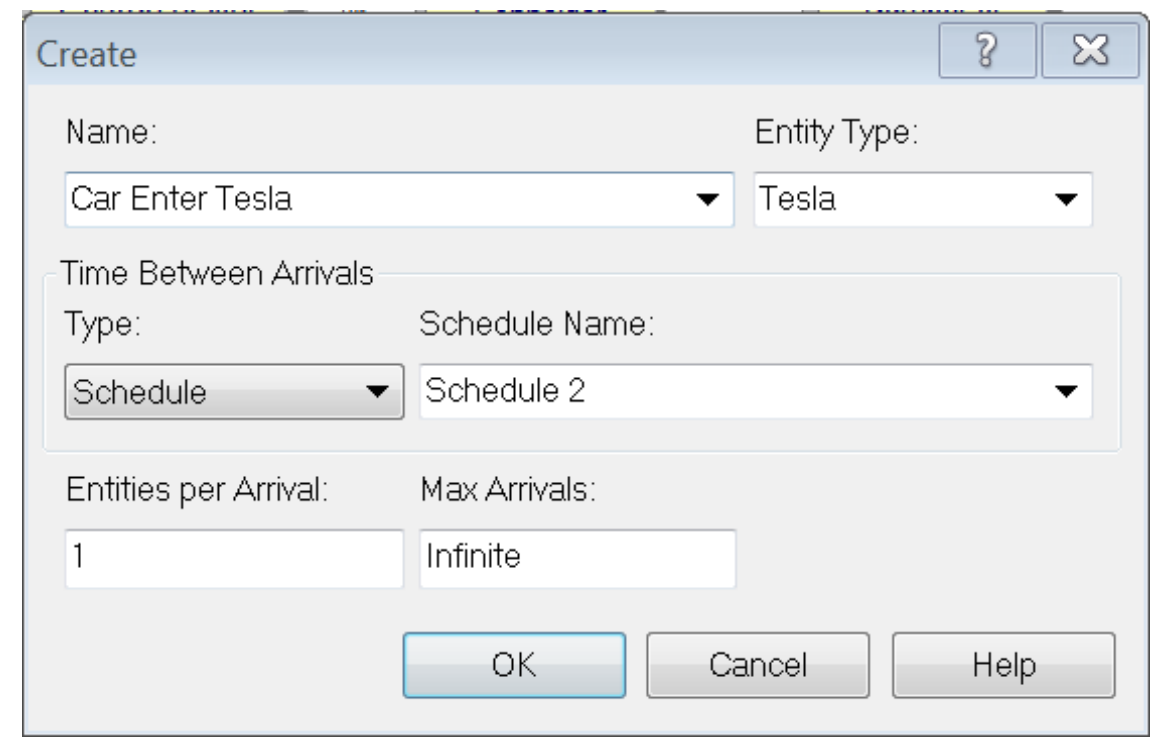

Figure 3.3. Create Module

The required variables in the simulation are assigned to both the allocated entities using an Assign module in the software. The current simulation time is assigned as a variable to each passing entity in this section. The software enabled the model, assigning a picture from the picture library of the software to each entity. Figure 3.4 shows the assignment of time variable and one picture to each type of entity.

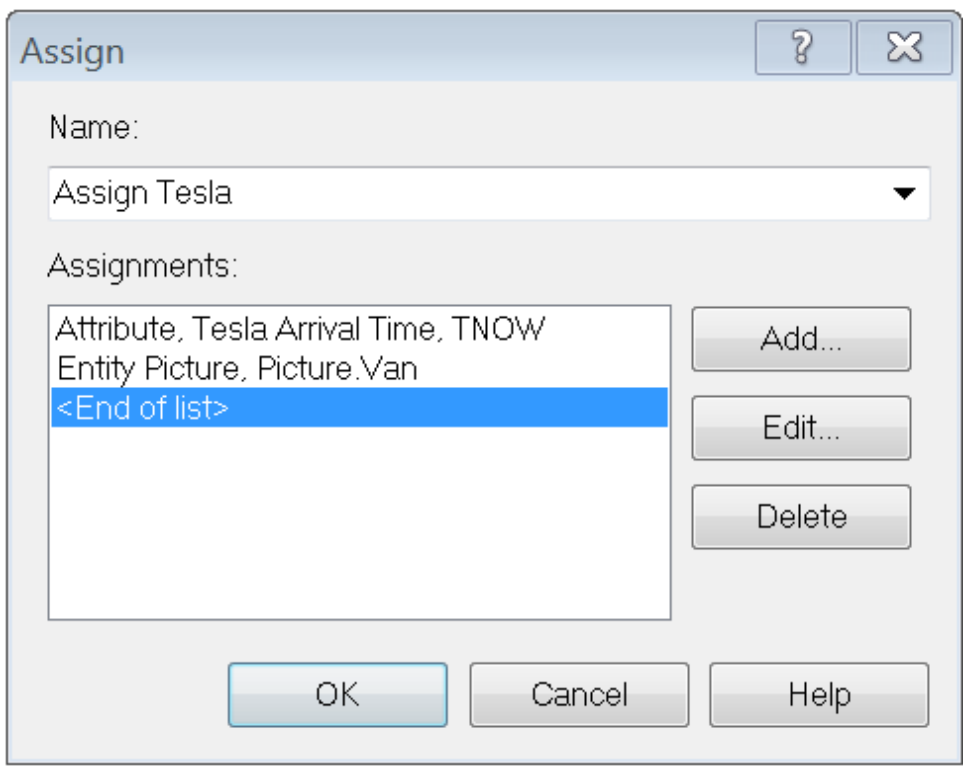

Figure 3.4. Assign module 
Further, the assigned entities are split using a decision module in the software which separates them based on type of entity. The decision module's condition by type is used to split the entities into individual channels. The condition considered is whether the incoming entity is of type Schneider ${ }^{\circledR}$ or not. This condition pushes the Schneider® type entities to Schneider ${ }^{\circledR}$ charging process if true and Tesla ${ }^{\circledR}$ type entities to Tesla ${ }^{\circledR}$ charging process if false. Figure 3.5 shows how the entities are split using a decision module.

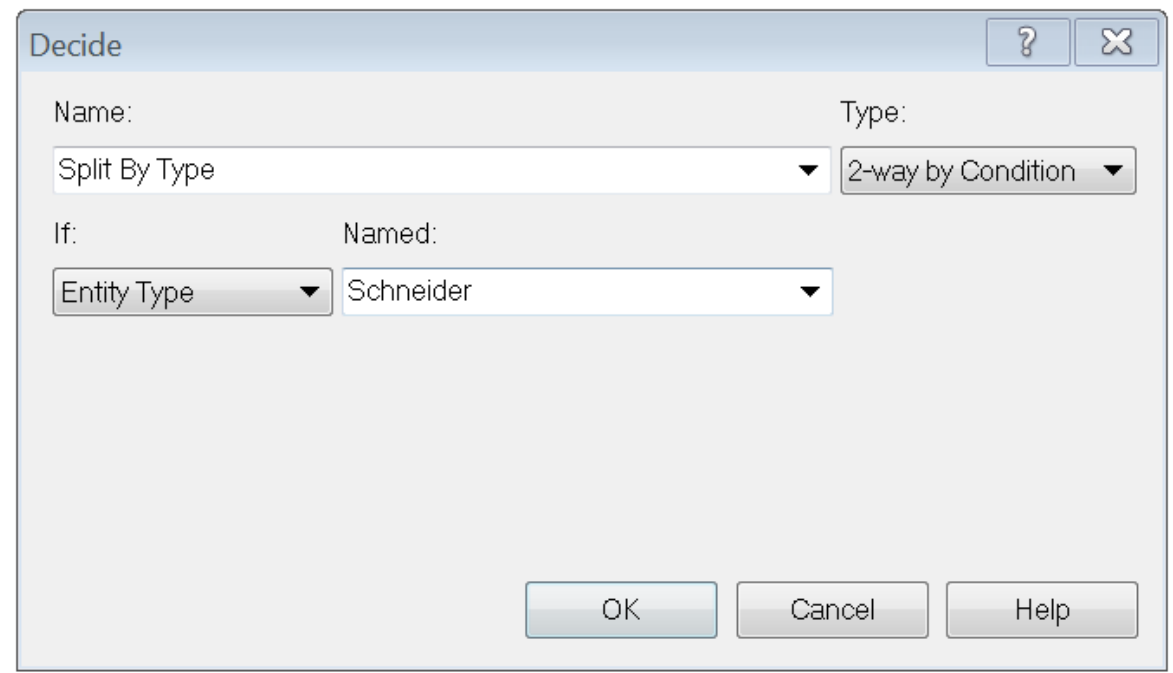

Figure 3.5. Entities Split by Type

\subsubsection{Decision Making}

The entities created, assigned and split by type are pushed to the next section of the simulation for decision making. Both the entities have different charging process modules. Each entity has to pass the decision making section to decide whether to charge or leave the facility. This is done using a decide module in the software. The rhombus shaped module in Figure 3.6 is the decide module and two different channels from it are also shown. The type on which this module has to choose is two way by condition. The deciding condition is based on a work in process (WIP) variable with an extension '.WIP', one for each entity type. The WIP variable for the entities of 
Schneider ${ }^{\circledR}$ type are named as 'Schneider ${ }^{\circledR}$ charging.WIP' and for the entities of Tesla ${ }^{\circledR}$ type ae named as 'Tesla® charging.WIP'.
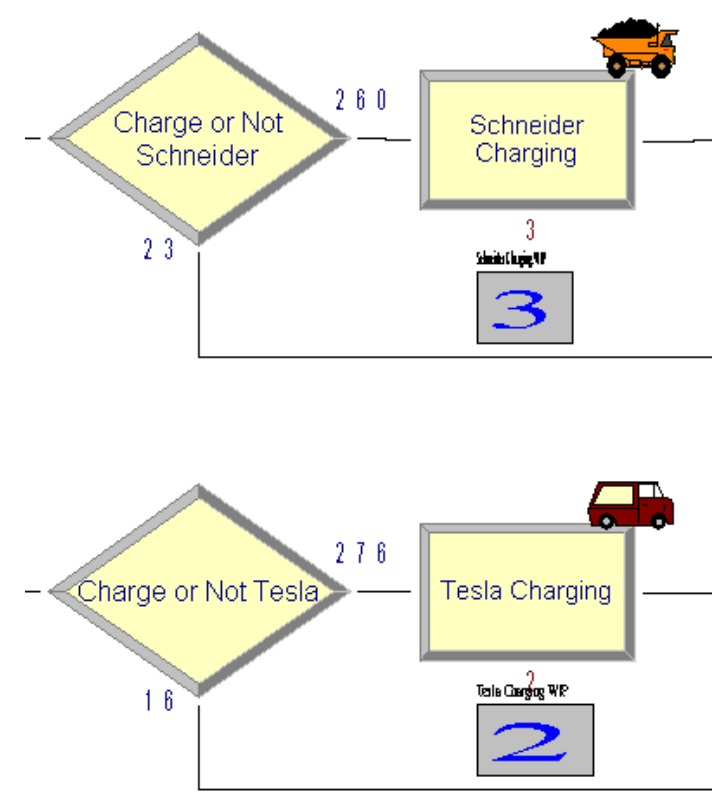

Figure 3.6. Decision Making for Both the Types

The WIP variable is an integer which indicates the number of entities on which the work is in process. So the condition is based on the number of entities that are in the charging process and those waiting to be charged after the decision making. This condition is developed on an assumption, considering the long charging durations. It is assumed that only one EV will be waiting to get charged when all the charging stations are occupied and the next EV arrived will leave the facility without charging. This assumption is modeled using a WIP variable and the decision module in the software. The entities waiting after the occupied charging stations are represented with a picture in queue on top of charging module as shown in Figure 3.6.

The facility considered in our research has one charging station to charge EVs of Tesla® type and two other charging stations for all the other type of EVs with universal charging port. So, the condition for decision making whether to charge or not for Tesla ${ }^{\circledR}$ EVs is formulated as the 
variable 'Tesla ${ }^{\circledR}$ charging.WIP' is less than or equal to 1 . And the condition for decision making whether to charge or not for other type EVs is formulated as the variable 'Schneider® charging.WIP' is less than or equal to 2. The decide module input is shown below in Figure 3.7. The false condition of the decide module represents the scenario of an entity leaving the simulation without charging when all the available charging stations are occupied and one more entity waiting to be charged. Whereas the true scenario represents an unoccupied charging station or an available waiting spot for the entity and hence enters the process module.

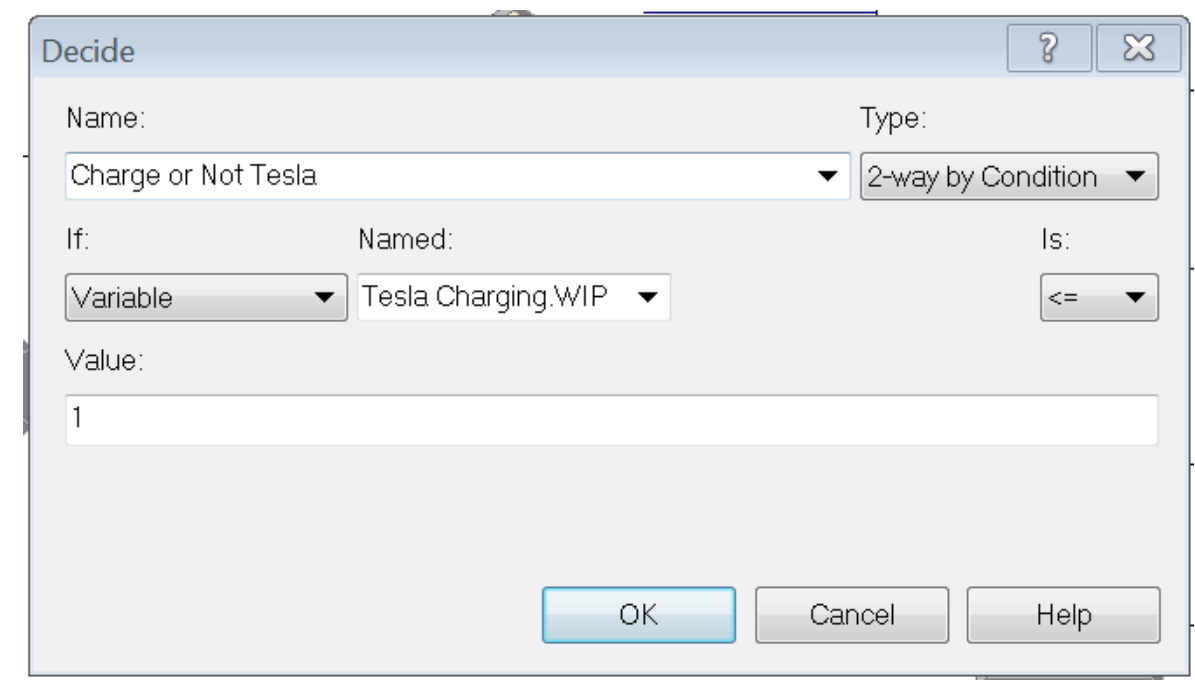

Figure 3.7. Decide Module for Tesla ${ }^{\circledR}$ EVs

\subsubsection{Charging Process}

Based on the input conditions, the entities that are decided by the model to charge are pushed into the charging process section and the rest are pushed out of the simulation as shown in Figure 3.8. The charging process is designed as a seize, delay and release action in the model with the help of a process module in the software. So, the process module logic performs seize, delay and release activities on each and every entity that passes through. The delay action in the module is a value added delay i.e., the time taken to process the entity. Hence, the time taken to charge the EV is modeled using this module, representing by the delay step in the process. This delay is a random 
variable time for every passing entity and can be input as a distribution using the pre-defined distributions in the process module.
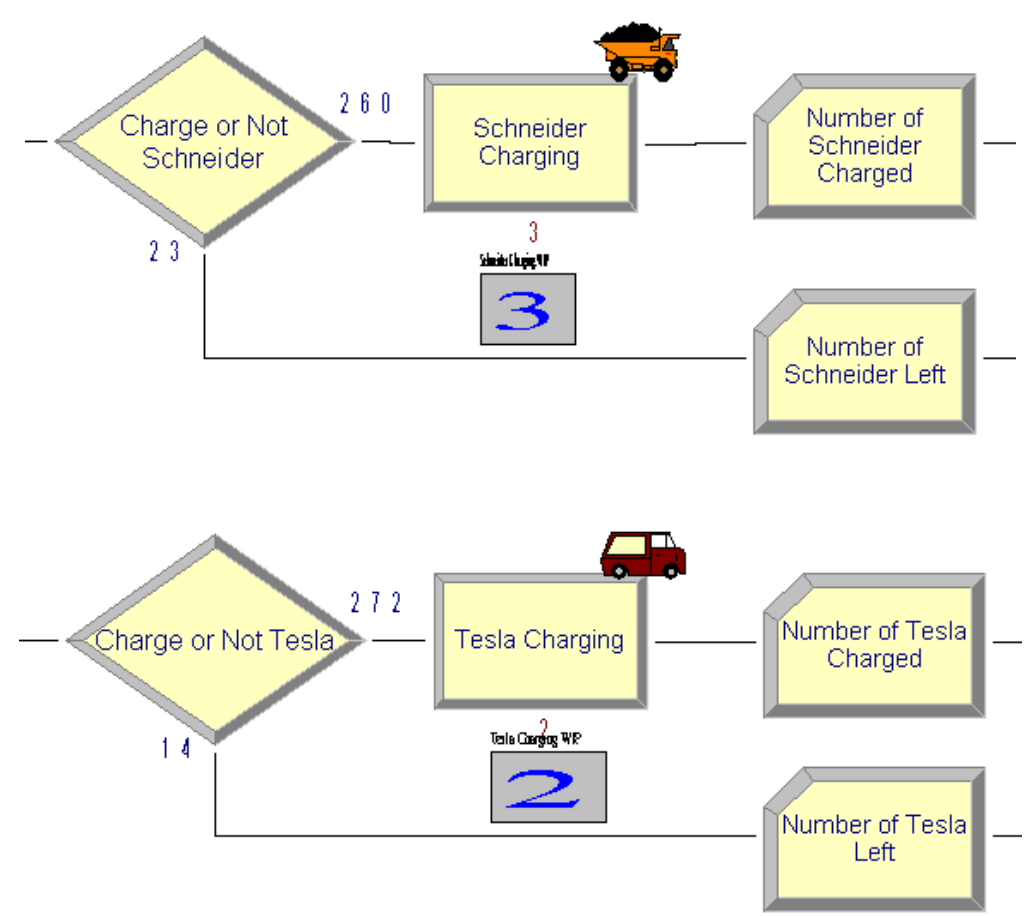

Figure 3.8. Charging Process

The charging times for any EV varies with the electrical operating characteristics mainly the maximum power. The calculations in this research are based on the operating details on the EVSE by its manufacturer at the public facility considered. Using these details, the charging duration for a Tesla ${ }^{\circledR}$ charger is estimated to be between 3 hours and 6 hours depending on the required charge in kilowatt-hours $(\mathrm{kWh})$. Whereas the charging duration for the Schneider ${ }^{\circledR}$ type of charger can vary from 2 to 6 hours. The required charge generally varies with the size of EV battery, the amount of charge left in the battery and the desired time an EV owner wants to charge. These times can vary randomly and hence this random variable is decided by the model dynamically using a triangular distribution (T- distribution). This can be shown for Schneider® type charging station and Tesla ${ }^{\circledR}$ type charging stations in Figure 3.9 and Figure 3.10 respectively. 


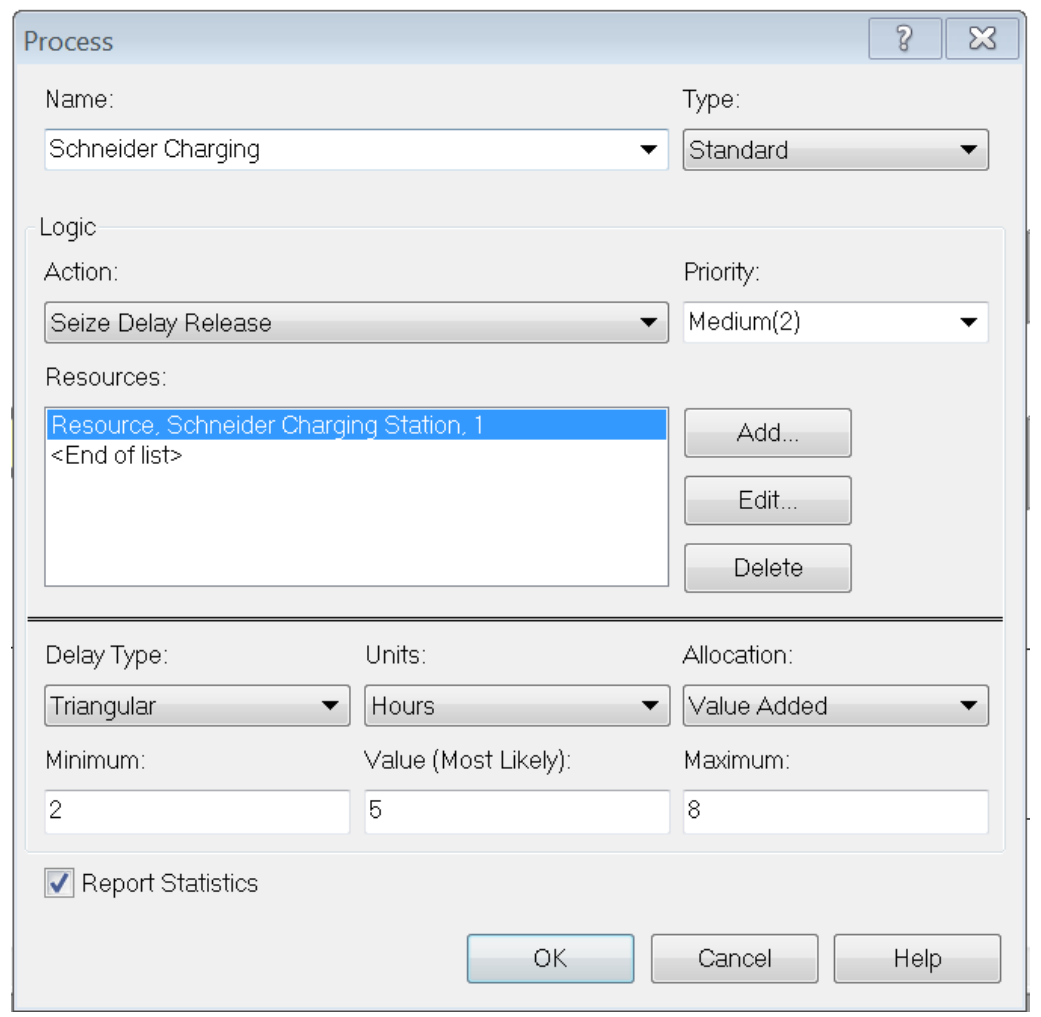

\section{Figure 3.9. Charging Process Module for Schneider ${ }^{\circledR}$ Type}

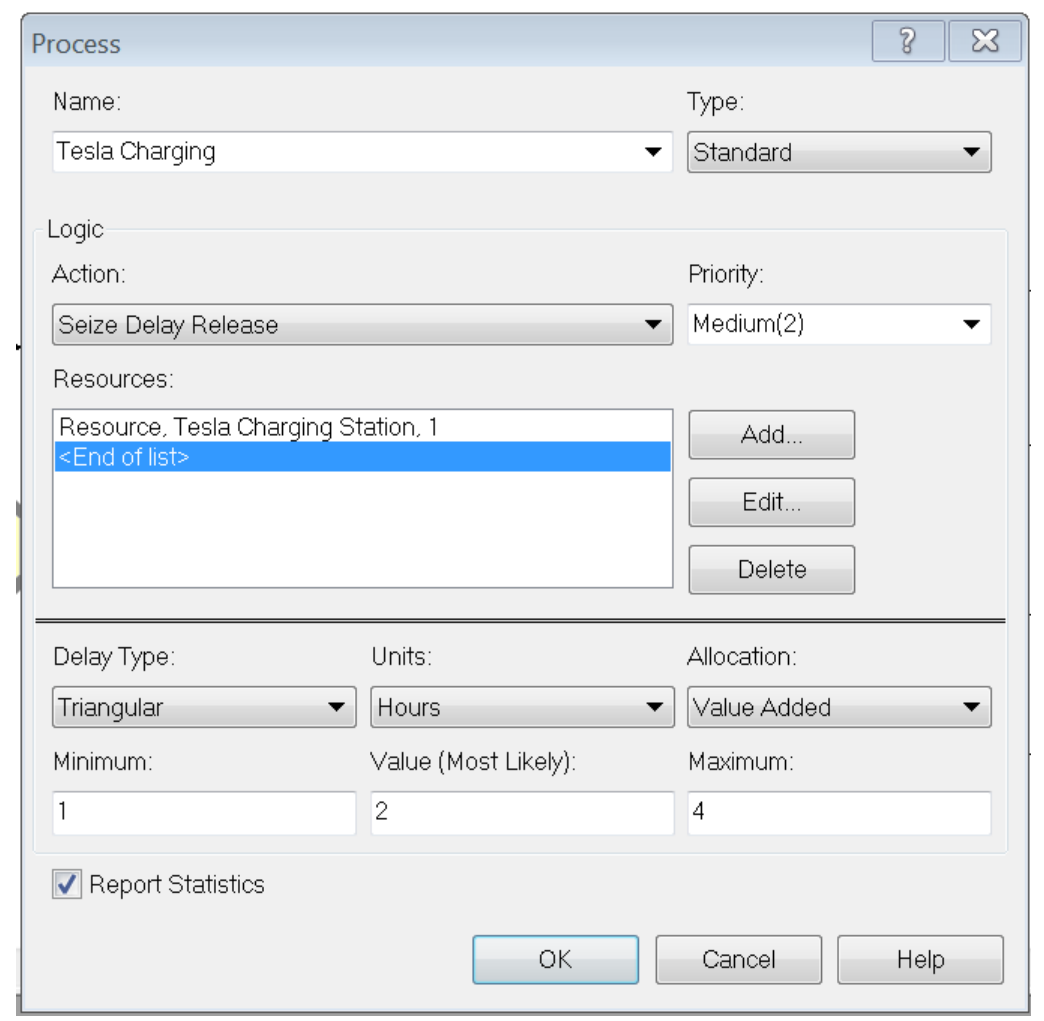

Figure 3.10.Charging Process Module for Tesla ${ }^{\circledR}$ Type 
Triangular distribution is a distribution similar to uniform distribution with a minimum value, a maximum value and a most likely value. It is employed in cases where the distribution of the random variables involved are vaguely known and with an understanding about the most likely outcome. The industry practice of using a uniform distribution can be improved by using the triangular distribution which gives lower probabilities of coming below the "most likely" value, higher probabilities of most likely value, and the possibility of maximum value. As the upper and lower limits of charging times are well known and their average being the most likely outcome in the distribution, $\mathrm{T}$ - distribution is considered to be closely representing the overall charging times.

The number of charging stations can be added as resources for a process module. Each entity will be processed by one resource in this model. Figure 3.11 shows two different types of resources of the model one for each type of entity. These represents the EVSE scenario in the public facility considered. So, the entities are seized, delayed by resources and released after the charging process modeling the charging pattern required. User can input the number of resources required in the simulation in this module.

\begin{tabular}{|l|l|l|l|}
\hline \multicolumn{2}{|l|}{ Resource Basic Process } & Type & Capacity \\
\hline & Name & Fixed Capacity & 2 \\
\hline 1 & Schneider Charging Station & Fixed Capacity & 1 \\
\hline 2 & Tesla Charging Station & Fixed Canacition &
\end{tabular}

Figure 3.11. Resources Involved in the Model

\subsubsection{Counters and Writing out Results}

The whole simulation run generates entities, decides to charge or not, and gets charged or leave the model replicating a charging pattern. But all the simulated data with values of different variables at times has to be counted and read out for further analysis. The entity and time interval counting is done using record modules in the software. The recorded data is written out to a 
spreadsheet with the help of read/write modules in the software. A read/write module and two record modules, one for counting entity numbers and the other for recording time interval data are included in each path of the model. All the entities that are proceeded to charge and those decided not to charge by the model leaves the simulation after recording and writing results through dispose modules in the software. All the modules involved in the final section of the simulation are shown in Figure 3.12 below.

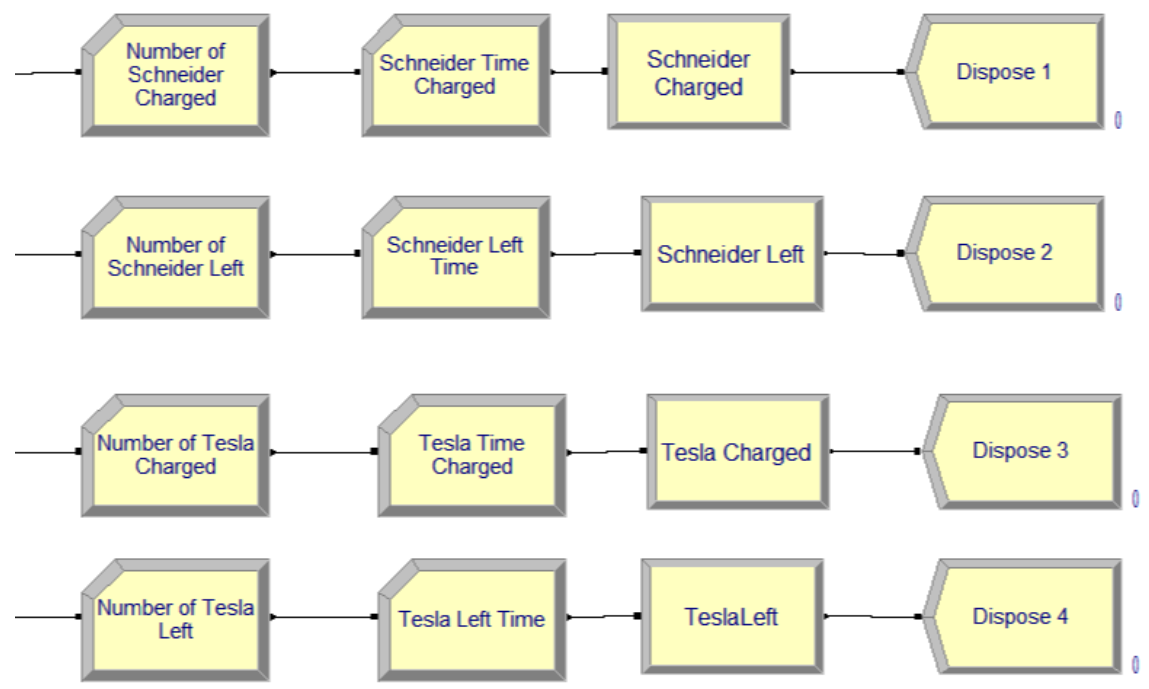

\section{Figure 3.12. Record, Read/Write, and Dispose Modules}

Simulated data from different variables like entity Id, Arrival times, wait times, Charging times, and total time stayed are written into a spreadsheet for further estimations and analysis. A cyclical process is created to record resource utilization data in each hour of a simulated year and are written out to another spreadsheet for estimating monthly energy consumption, electrical demand and charges associated with them for both types of entities. 


\subsection{Annual Energy Costs and Electrical Demand Estimates}

In this model, energy consumption and cost estimates per entity, per each simulated hour and per each month for a year are estimated. Electrical load in terms of Demand in kilowatts $(\mathrm{kW})$ is also simulated for each hour to understand the load pattern.

\subsubsection{Energy Consumption and Costs}

The model is capable of estimating the kilowatt hour $(\mathrm{kWh})$ energy consumption and costs for two different types of EVs separately for each simulated entity. In this estimation charging time in hours from the ARENA® simulated data output spreadsheet and operating power of the charging station in the facility considered based on the type of EV are used. The charging stations at the facility considered are supplied with $240 \mathrm{~V}$ single phase AC current. As per the manufacturing details, both types of AC Level 2 charging stations considered operate on single phase electric supply and the operating power is estimated using the operating characteristics like maximum amperage and operating voltage on the manufacturer's name plate. The operating power of the Schneider ${ }^{\circledR}$ charging station is 7.2 kilowatts $(\mathrm{kW})$ and that for Tesla® charging station is $17.2 \mathrm{~kW}$. In this model, the energy consumption $(\mathrm{kWh})$ of each simulated entity based on type in $\mathrm{kWh}$ is obtained by multiplying Charging time $\left(\mathrm{T}_{\mathrm{C}}\right)$ of the entity in hours with the Operating power $(\mathrm{P})$ of respective charging station. Energy costs (EC) are obtained by multiplying the obtained kWh with energy charge $(\$ / \mathrm{kWh})$ from the rate structure (Table 3.4). The relations used for estimation are shown below.

$$
\begin{gathered}
\mathrm{kWh}=\mathrm{T}_{\mathrm{C}} \times \mathrm{P} \\
\mathrm{EC}=\mathrm{kWh} \times \$ / \mathrm{kWh}
\end{gathered}
$$

The energy consumption and costs for each month of a calendar year can also be estimated using this model. For this, the hourly data generated using a cyclical process in the model is used. The 
simulated percent utilization data of the resources i.e. charging stations in our case, Operating power $(\mathrm{P})$ of respective charging station and one hour of duration are multiplied together to obtain the energy consumption of each hour in an year. Operating powers used for Schneider® and Tesla ${ }^{\circledR}$ charging stations are $7.2 \mathrm{~kW}$ and $17.2 \mathrm{~kW}$ respectively. The hourly energy consumption data obtained is briefed for 12 individual calendar months. This monthly $\mathrm{kWh}$ consumption obtained is multiplied with the energy rate as per Table 3.4 to estimate the monthly energy costs resulted after charging the simulated EV arrivals for respective times following a T-distribution.

Table 3.4.Rate structure for the Facility Considered

\begin{tabular}{|l|c|c|}
\hline \multicolumn{3}{|c|}{ Rate structure for the Facility Considered } \\
\hline \multirow{2}{*}{ Electricity } & $\$ / \mathbf{k W h}$ & $\mathbf{0 . 0 5 2 6}$ \\
\cline { 2 - 3 } & $\$ / \mathrm{kW}$ & 11.508 \\
\hline
\end{tabular}

\subsubsection{Electrical Peak Load and Demand Costs}

For estimating the monthly peak demand on which the facilities are billed, rolling peaks are needed. In this model, the rolling peaks established by all the facility buildings together and those by charging stations for every one hour are estimated due to data constraints. Demand peak by the buildings is simulated based on the user input on maximum and minimum monthly demand peaks in kilowatts established over the past year. Whereas the charging station demand estimates are based on the simulated utilization data of the charging stations obtained using a cyclical process. Electrical load at the time of use for each hour is estimated by multiplying the number of resources in utilization at the time $(\mathrm{NR})$ of each type with the Operating power $(\mathrm{P})$ of respective charging station. Monthly peak demand is the maximum of the rolling hourly total demands, which is the sum of demand peaks established by buildings and charging stations in that hour for a month. Peak demand for each month on which the facilities are billed on this peak total demand obtained. 
To estimate the effect of charging stations on the demand and demand costs, load contributed by the charging stations in use at the time of peak total establishment is to be obtained. To obtain this load contribution, time at which simulated demand data of each month is maximum has to be known. Demand developed at that particular point of time will be the demand contributed by the charging stations. Demand costs (DC) are obtained by multiplying the obtained monthly peak total demands with Demand charge $(\$ / \mathrm{kW})$ from the rate structure (Table 3.4). Demand costs contributed by the charging stations ( $\mathrm{DC}_{\mathrm{CS}}$ ) can be estimated by multiplying their load contribution at the peak total demand hour $\left(L_{P}\right)$ with demand charges. The relations used for estimation are shown below.

$$
\begin{gathered}
\mathrm{kW}=\mathrm{NR} \times \mathrm{P} \\
\mathrm{DC}=\text { Peak total demand } \mathrm{x} \$ / \mathrm{kW} \\
\mathrm{DC}_{\mathrm{CS}}=\mathrm{LP}_{\mathrm{P}} \times \$ / \mathrm{kW}
\end{gathered}
$$

Using the Energy Costs and the Demand Costs, the total costs for the electricity supplied to charge all the simulated EV arrivals for corresponding charging times is estimated. The total costs (TC) in dollars are the sum of Energy Costs (EC) and the Demand Costs (DC) as shown in the following relation.

$$
\mathrm{TC}=\mathrm{EC}+\mathrm{DC}
$$

Using this relation, total costs for charging Tesla ${ }^{\circledR}$ and other regular EV arrivals are calculated separately and also the total costs for the facility considered with three charging stations are estimated for individual months for a year. 


\subsection{Limitations}

This section explains different assumptions made in various stages of the model and the limitations of the overall model developed.

1. Simulation of EV arrivals depending on weather severity and time of the year on the basis of maximum and minimum EV arrivals in the past.

2. The model is capable of simulating only a large time slot of one hour instead of a few minutes.

3. Demand analysis is performed for one hour rolling peaks instead of 15 minute rolling peaks.

\subsection{Conclusion}

This chapter explains the problem this research is addressing to, and the approach we are following to simulate the EV arrival and charging patterns in the initial sections. Various methods and software tools used to meet the objectives in this work are discussed in the later sections. All the steps involved in development of the first half of the work, the EV arrival pattern spreadsheet model are elucidated. The capabilities of this spreadsheet model and various factors considered in the process are discussed in detail. Charging pattern model by simulation using ARENA® simulation software and different modules in the simulation model are explained with the help of figures and tables. The calculations involved in Energy consumption, monthly peak demand and electricity supply costs associated for the simulated year are explained. Assumptions made in the development of the models and their limitations are listed in the end of this chapter. 


\section{System Execution and Results Discussion}

This chapter considers a sample simulation to explain the models and how a user should proceed till the end of the simulation. Different results obtained and corresponding graphs are presented. Sensitivity analysis of electrical demand and supply costs with varying weather severity and number of charging stations.

\subsection{Energy Assessment at a Public Facility}

Electric utility providers bill the facilities on a commercial rate schedule which decides the rate structure charges for the energy consumption, demand charges and other charges. The facility considered in this study has an energy consumption of 7,516,720 kWh in the year 2015 . The purpose of this energy assessment is to evaluate the possibility of getting into a better rate schedule by reducing their baseline energy consumption. As a part of the energy assessment, utility bill analysis was performed to understand their energy consumption by the major energy consumers in different months and estimate the average costs of energy consumption and demand. The rate structure obtained was reported in Table 3.4 for cost estimates after the simulation.

\subsection{Electric Vehicle arrival pattern spreadsheet model with Sample Inputs}

The first part of the simulation is the EV arrival pattern generation using the spreadsheet model developed by giving inputs to the model. The first step of the simulation is to clear the existing data in the spreadsheet model. The simulated data from the previous runs can be cleared by clicking the button saying 'Clear data'. After clearing the data from previous runs, user can start the simulation by clicking the button saying 'Generate EV Arrivals'. This generates a message box requesting for minimum number of EVs arriving on any day over the past. Once the minimum number of EV arrivals are entered, the model promptly requests for maximum number of EVs arriving on any day over the past in a message box. After answering the maximum arrivals, it 
requests for probability of Tesla® $\mathrm{EV}$ arrivals around a year as a fraction. Once the fraction input was given, another message box appears requesting for probability of weather severity as a fraction. On answering the last input, model simulates the EV arrival pattern with number of EV arrivals of each type per each day for a year. Consider the inputs for minimum arrivals, maximum arrivals, probability of Tesla ${ }^{\circledR}$ EVs and Weather severity probability as $0,10,0.4$ and 0.3 respectively as shown in Figure 4.1.

\begin{tabular}{|c|c|c|c|}
\hline Minimum arrivals & $\times$ & Maximum arrivals & $\times$ \\
\hline \multirow{2}{*}{$\begin{array}{l}\text { Minimum number of Electric Vehicles arriving on } \\
\text { any day over the past? Please enter a number } \\
\text { between } 0 \text { and } 30,000\end{array}$} & OK & \multirow{2}{*}{$\begin{array}{l}\text { Maximum number of Electric Vehicles arriving on } \\
\text { any day over the past? Please enter a number } \\
\text { between } 0 \text { and } 30,000\end{array}$} & $\mathrm{OK}$ \\
\hline & Cancel & & Cancel \\
\hline \multicolumn{2}{|l|}{0} & \multicolumn{2}{|l|}{10} \\
\hline Fraction of Tesla vehicles & $\times$ & Fraction of Severe Weather & $\times$ \\
\hline \multirow{2}{*}{$\begin{array}{l}\text { Probability of Tesla Vehicles arriving round the } \\
\text { year? Please enter a fraction between } 0 \text { and } 1\end{array}$} & OK & \multirow{2}{*}{$\begin{array}{l}\text { Probability of Severe Weather conditions round } \\
\text { the year? Please enter a fraction between } 0 \text { and } 1\end{array}$} & OK \\
\hline & Cancel & & Cancel \\
\hline \multicolumn{2}{|l|}{0.4} & \multicolumn{2}{|l|}{0,3} \\
\hline
\end{tabular}

\section{Figure 4.1. Input Boxes for EV Arrival Pattern}

Arrival patterns as plots with number of EV arrivals of each type against 365 days in a year are also generated a shown in Figure 4.2. After generating the EV arrivals, the user have to generate arrival times for Regular EV and Tesla® EVs by clicking on 'Generate Regular EV Times' button and 'Generate Tesla® EV Times' button respectively one after the other. This generates the arrival times for both types of EVs in separate sheets. Histogram showing monthly EV arrivals with both type EVs and total EVs data will be generated as shown in Figure 4.3. After getting arrival times, user is supposed to generate schedule for $A R E N A ®$ simulation based on the generated arrival times by clicking 'Generate Arena Input' button on 'Arrival Pattern' spreadsheet. 


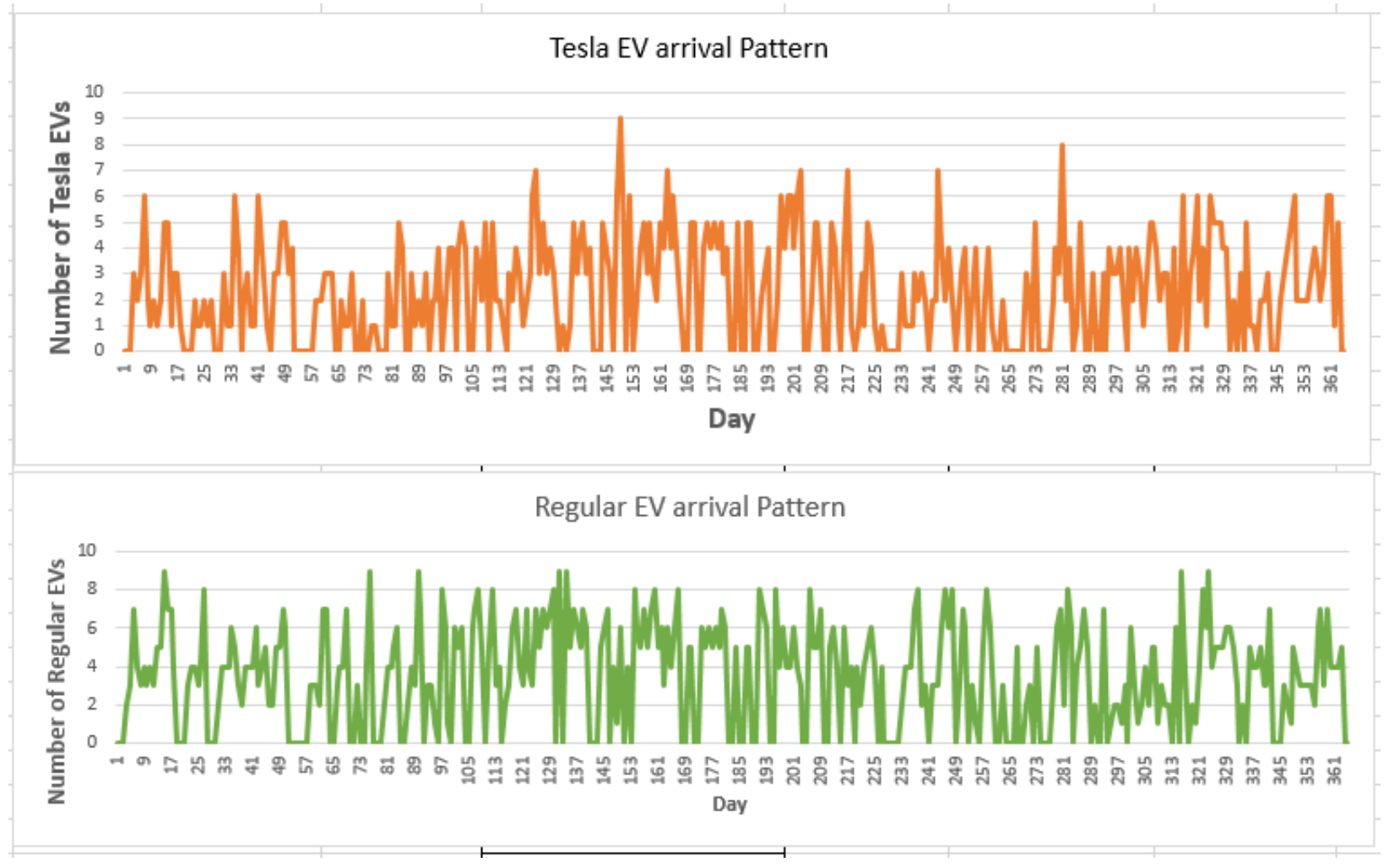

Figure 4.2. EV Arrival Patterns

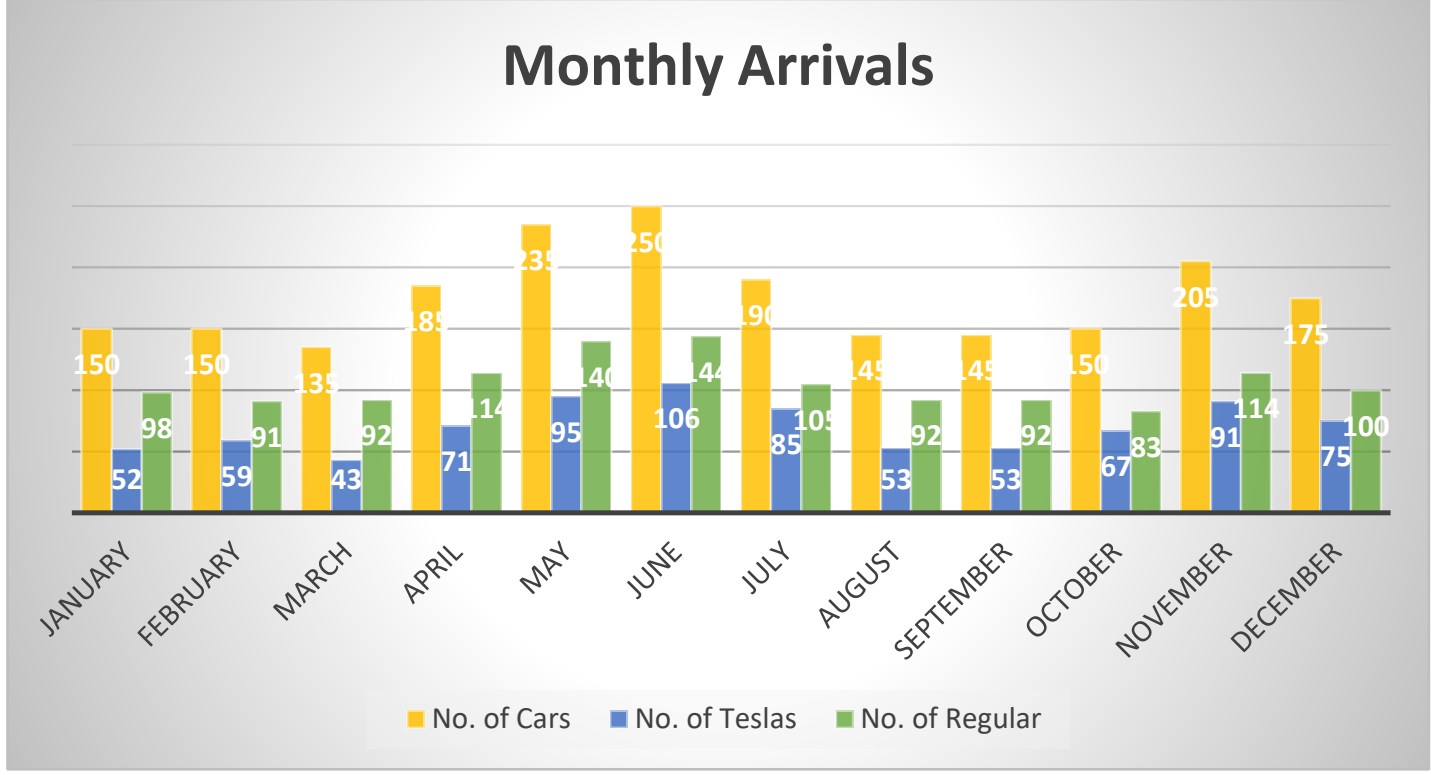

Figure 4.3.Histogram representing Monthly EV Arrivals 


\subsection{Charging Pattern and Logistics Modelling Simulation with Sample Inputs}

The input schedule generated for EVs of both the types has to be input in schedule module of the charging pattern simulation model. Resources i.e. charging stations can be modified in the resource module of the model. For our simulation, two Schneider ${ }^{\circledR}$ charging stations and a Tesla ${ }^{\circledR}$ charging station are reflected as in the facility considered for our work. The simulation is then run which generates two output files at the end.

\subsubsection{Energy Consumption}

The first output spreadsheet file gives the energy consumption and the energy costs associated per each EV for both the types. It displays the data for arrival times, wait times, and charging times beside each EV entity for all the EVs charged in individual spreadsheets for each type of EV. The second output file has the resource utilization and energy consumption for each hour for a simulated year. The model also generates monthly energy consumption for charging stations of both the types. Total facility energy consumption and costs are also generated for each month in a year and a histograms were plotted separately.

\subsubsection{Electrical Demand}

The spreadsheet 'Demand' in the second output file displays the electrical load by the charging stations of each type and the total demand for each hour for a year. Building load is simulated and total demand is estimated automatically in the same spreadsheet alongside for every hour in a simulated year. Rolling total demand is generated and plotted for each hour in a year. Monthly peak demand is the maximum of rolling one hour total peaks for that month. Demand costs contributed by the charging stations ( $\mathrm{DC}_{\mathrm{CS}}$ ) can be estimated by multiplying their load contribution at the peak total demand hour $\left(\mathrm{L}_{\mathrm{P}}\right)$ with demand charges. Monthly peak demands and costs associated with them are also generated and plotted separately. 


\subsubsection{Total Electric costs}

The model is capable of estimating the total electric supply costs as the sum of energy and demand costs.

\subsection{Sensitivity Analysis}

The effects on energy consumption, demand and total costs with variation of probabilities of weather severity and different number of charging stations are analyzed. The results generated by keeping all the other variables constant and other than the required one are plotted and analyzed.

\subsubsection{Weather Severity}

To observe the effect of weather severity variation on energy consumption, demand and costs associated a graphs showing monthly energy consumption, demand and total costs are plotted varying the probability of weather severity keeping same number of minimum arrivals, maximum arrivals and probability of Tesla ${ }^{\circledR}$ EVs constant. Two simulation runs are performed with probability of weather severity values considered to be 0.5 and 0.4 with number of minimum arrivals, maximum arrivals and probability of Tesla® EVs to be 0,5 and 0.3 respectively. The graphs for Monthly peak demand, demand costs and monthly costs for the considered number of charging stations are plotted below as Figure 4.4, Figure 4.5 and Figure 4.6 respectively. 


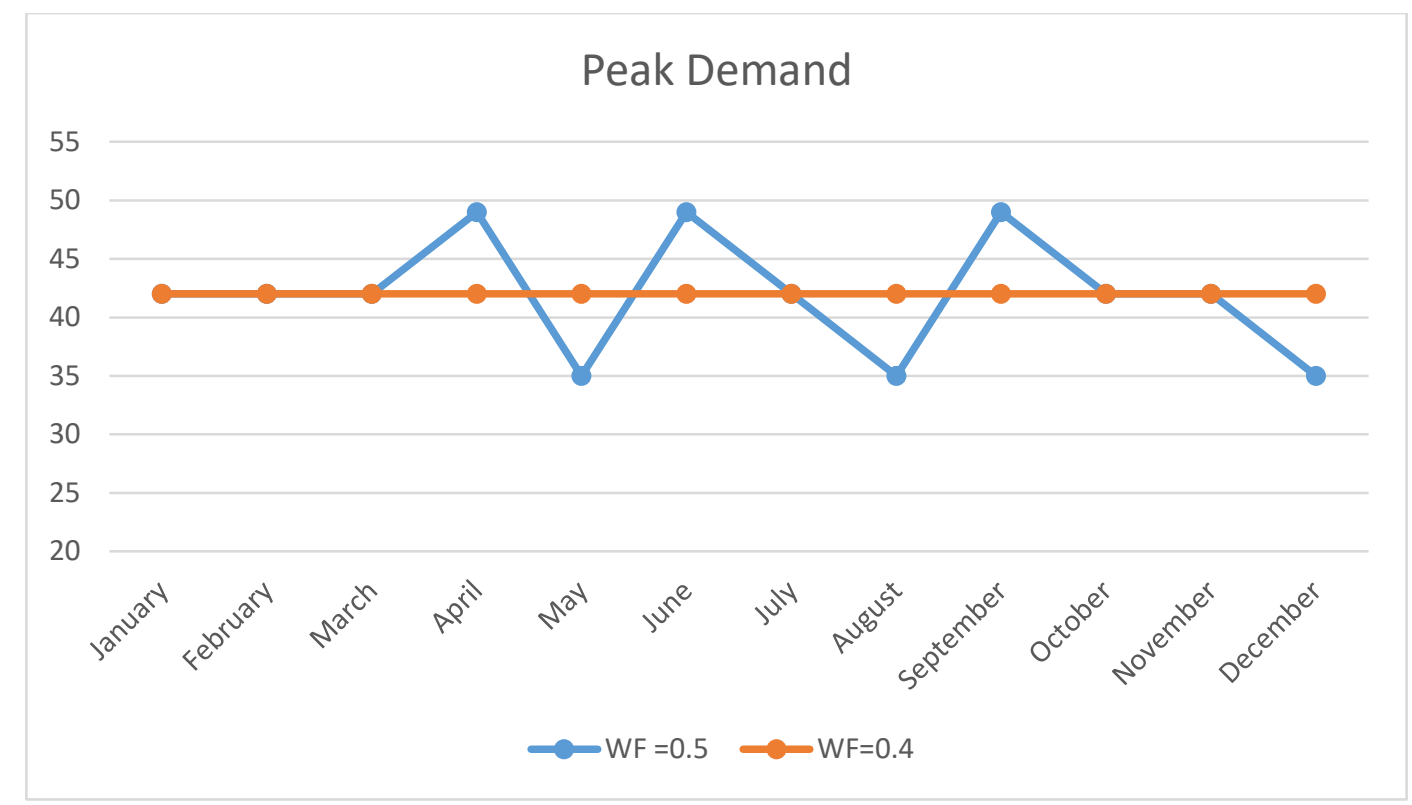

Figure 4.4. Monthly peak Demand Vs Weather Severity

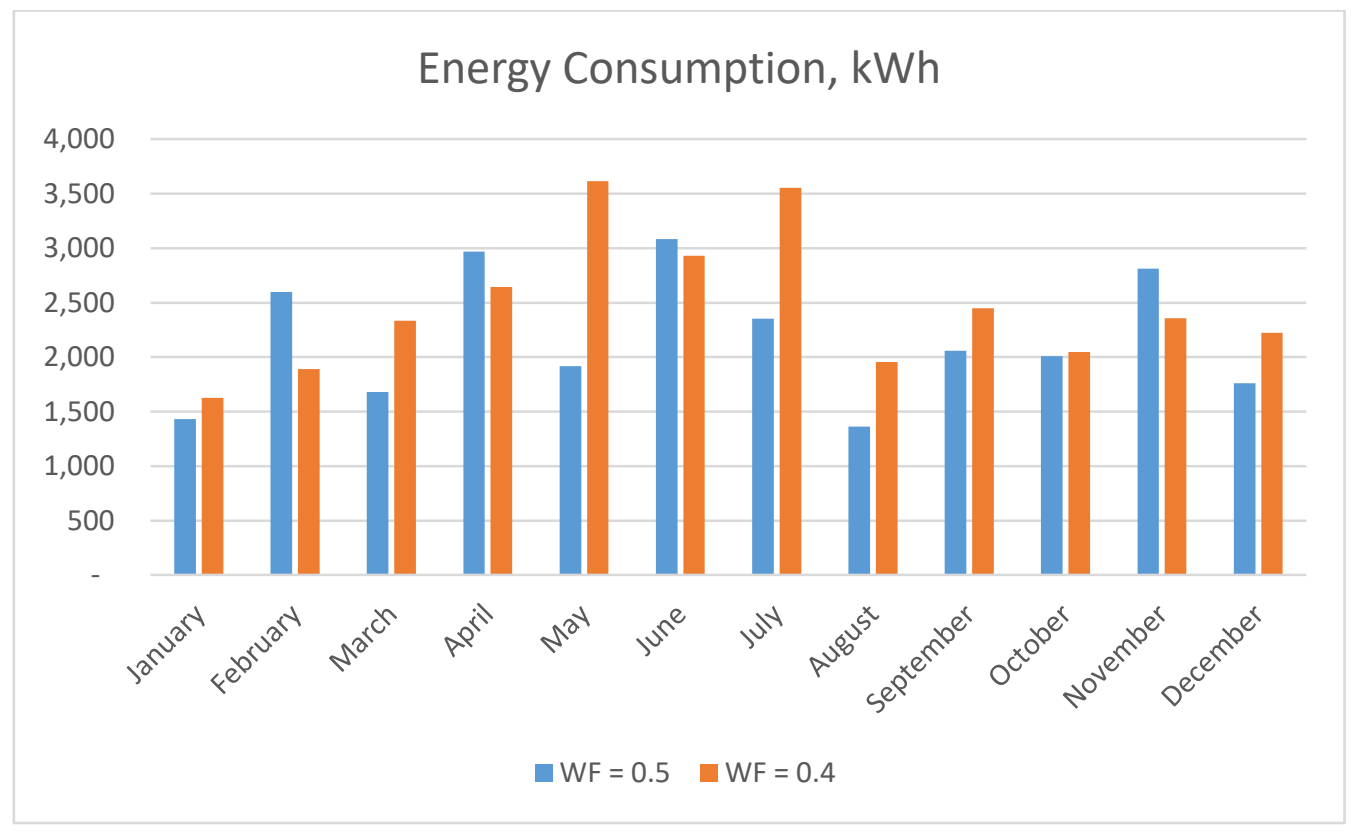

Figure 4.5. Energy Consumption Vs Weather 


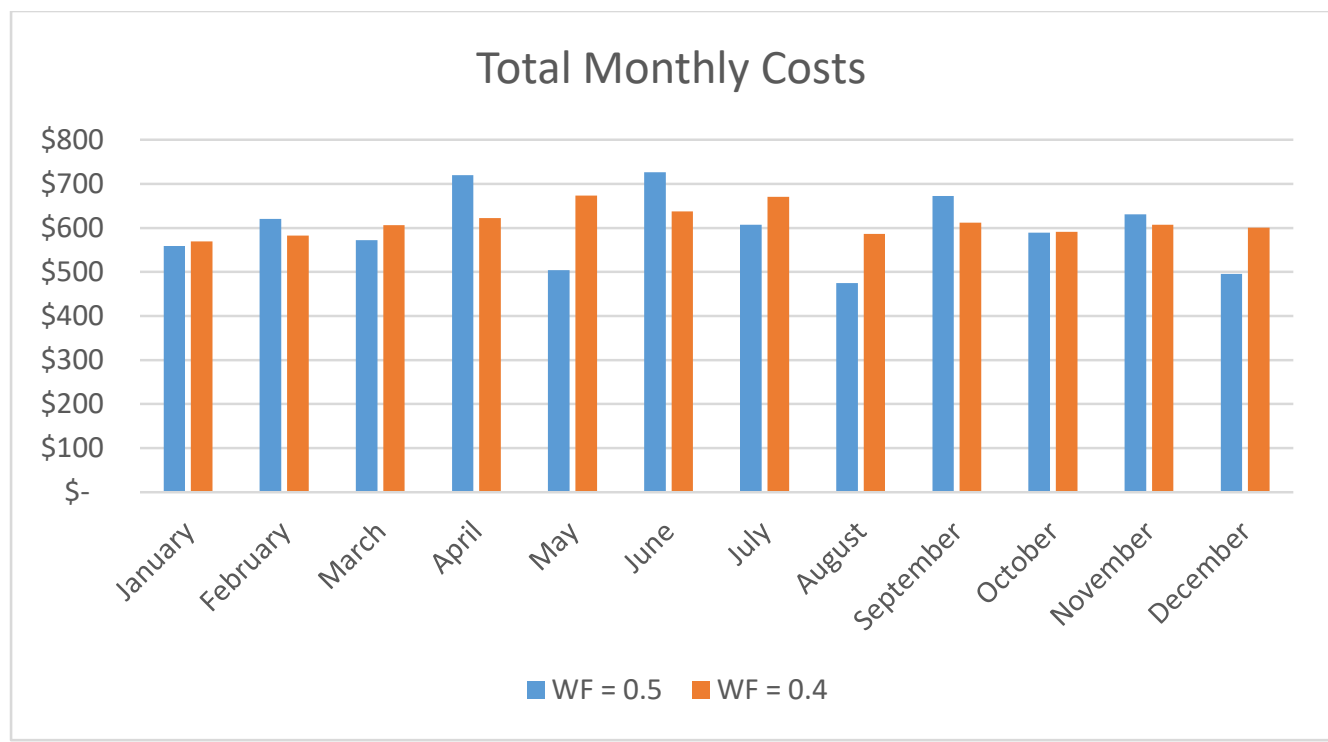

Figure 4.6. Total Monthly Costs Vs Weather

\subsubsection{Number of Charging Stations}

To observe the effect on energy consumption, demand and costs associated by varying number of charging stations, graphs showing monthly energy consumption, demand and total costs are plotted varying number of charging stations keeping the number of minimum arrivals, maximum arrivals, probability of Tesla ${ }^{\circledR}$ EVs and Weather severity constant. Three simulation runs are performed with probability of weather severity values considered to be 0.3 and with number of minimum arrivals, maximum arrivals and probability of Tesla® EVs to be 0,5 and 0.3 respectively.

1. One Tesla® Charging Station and One Schneider ${ }^{\circledR}$ Charging Station

2. Two Tesla ${ }^{\circledR}$ Charging Stations and Three Schneider® Charging Stations

3. One Tesla ${ }^{\circledR}$ Charging Station and Two Schneider® Charging Stations

The graphs for Monthly peak demand, demand costs and monthly costs for the considered number of charging stations are plotted below as Figure 4.7, Figure 4.8 and Figure 4.9 respectively. 


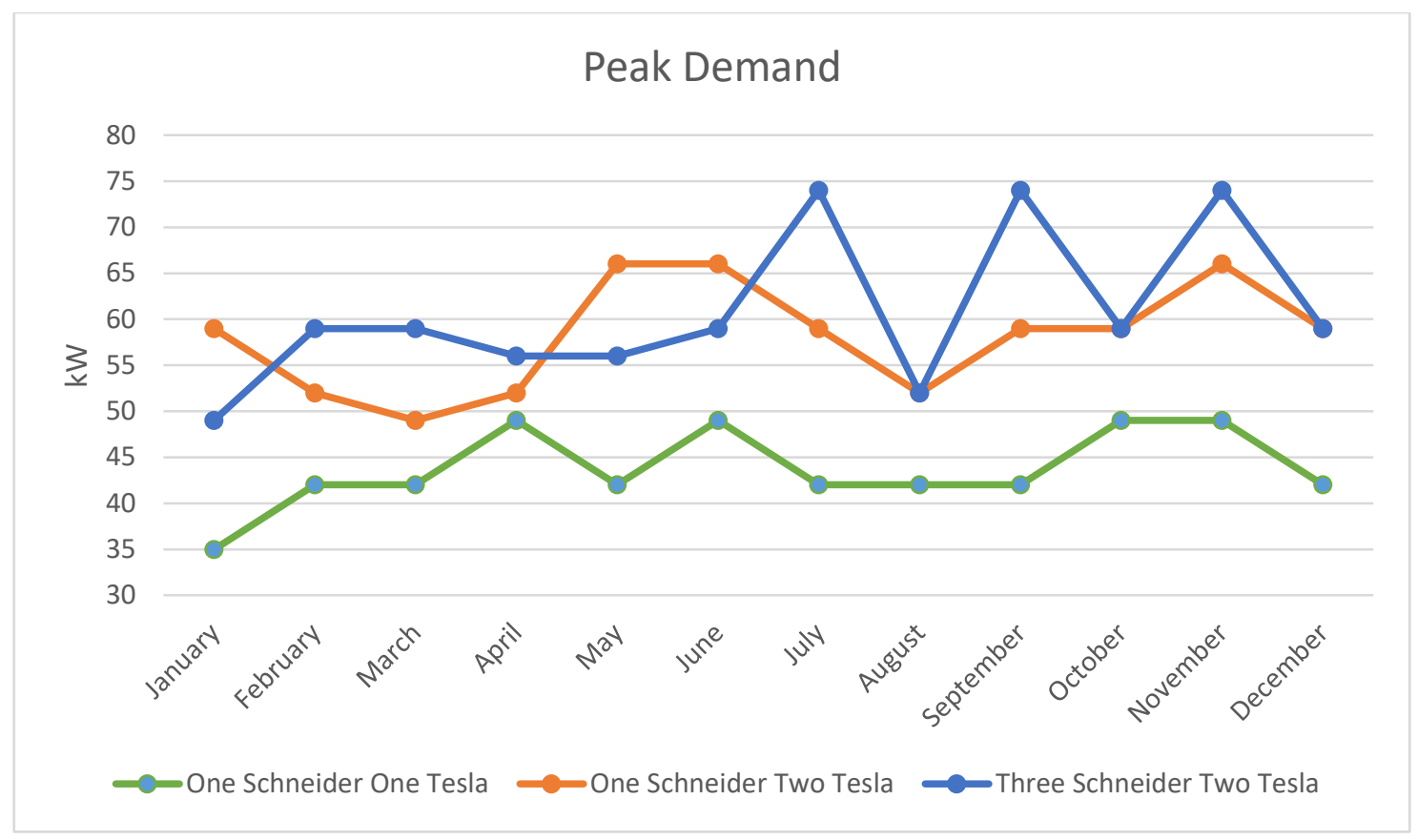

Figure 4.7. Peak Demand Vs Number of Charging Stations

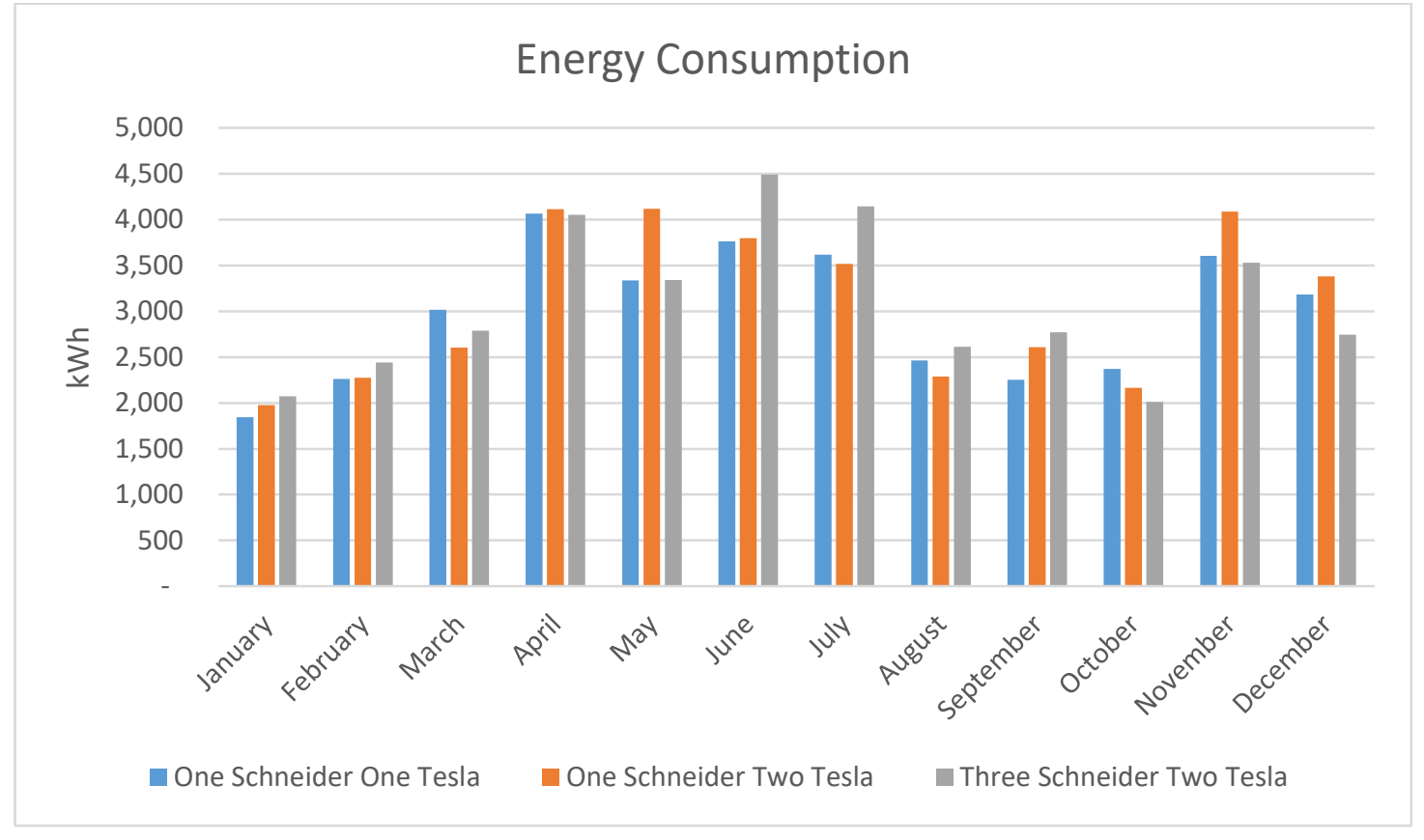

Figure 4.8. Energy Consumption Vs Number of Charging Stations 


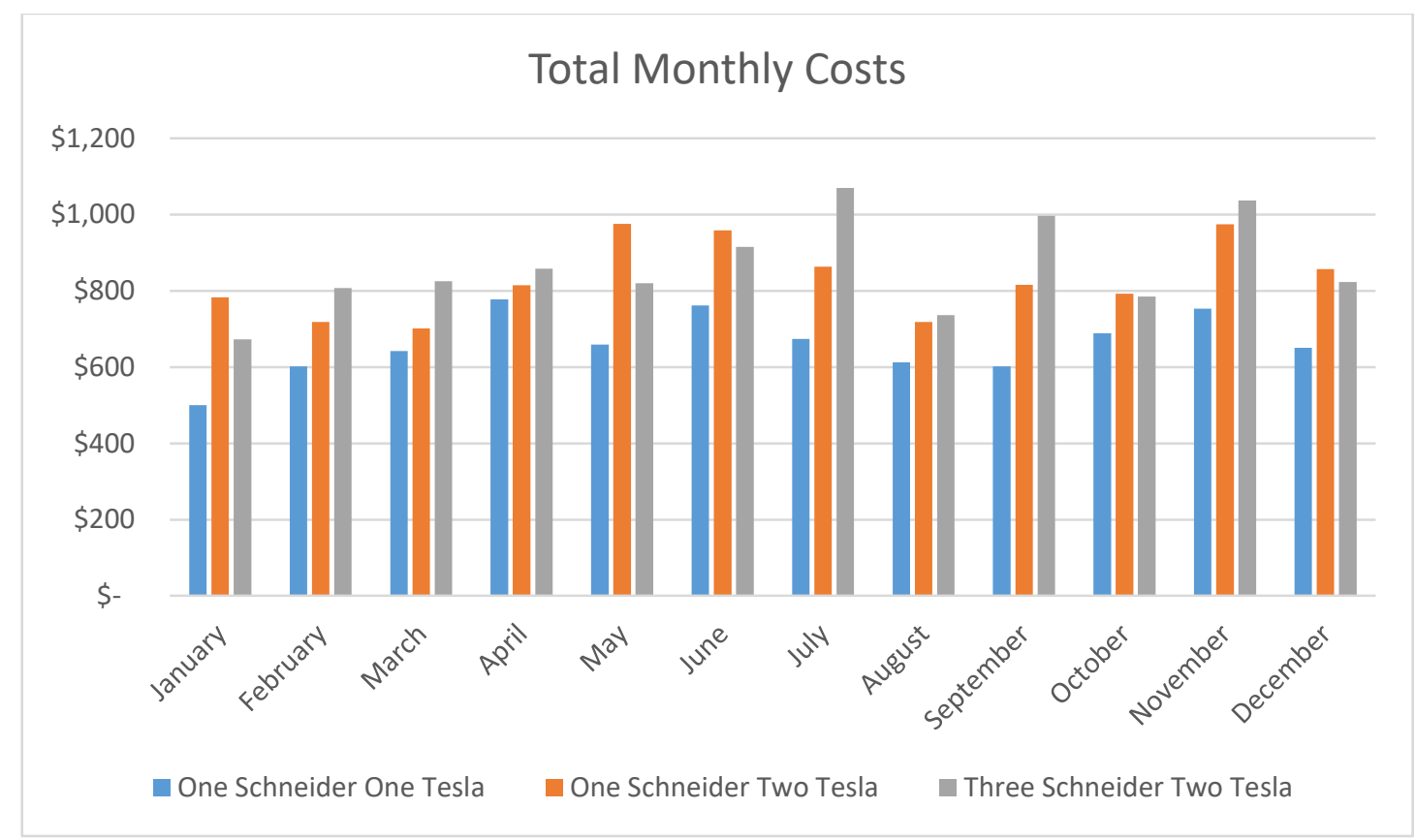

Figure 4.9. Total Monthly Costs Vs Number of Charging Stations

\section{Conclusions and Future Work}

\subsection{Conclusions}

This research focused on forecasting the arrival traffic density and charging pattern of Plug-in Electric Vehicles (PEVs) based on pertinent factors across various seasons and holidays over a year. A Monte Carlo simulation of a scenario depicting traffic arrival patterns using various prerecorded and categorical data and based on weather Severity and time of the year. A discrete event simulation modelling the charging patterns of the EV arrivals based on the arrival pattern generated.

Demand analysis of the considered public facility based on electrical supply requirements over different times of the year is performed to curtail demand and save on demand charges. The 
possibility of rate schedule change to reduce demand charges with the addition of charging stations can be evaluated using the simulated data. The facility considered in the study was already being billed on the utility provider's largest demand drawing facilities' rate schedule. The kilowatt demand data from multiple simulation runs performed is more than the existing larger peak demand and hence can only be billed on the same rate schedule. So it is observed that, this facility cannot reduce demand charges by changing the existing rate schedule.

It is observed that the electrical peak demand established by the facility for a month depends not only on the number of existing charging stations, number of cars charging at the same time, but also on the peak demand established by rest of the buildings. In this study, there are times, in which charging stations and the buildings together contribute the peak demand and those in which buildings alone establish the peak. This tool is capable of estimating the total demand generated and demand drawn by the charging stations and the buildings separately for every hour in a simulated year. This demand analysis helps the user understand the demand behavior at different times and take appropriate strategic decisions to curtail the monthly peak demand. The simulated energy consumption, demand and costs associated obtained can support a decision on the optimal number of charging stations to be established in a public facility which are sustainable and economically viable.

\subsection{Future Work}

Influence of other factors like availability of historic places, public attractions and commercial facilities near the public facility can be evaluated. EV arrival density at different time slots is considered constant in the model. Variations in arrival density with different times of the day can be evaluated further. Demand analysis is performed for one hour time intervals due to the constraints in data size. This can be improved by estimating demand for fifteen minute intervals 
for even accurate estimates of peak demand and costs incurred. Capital, installation and maintenance costs involved with establishment of charging infrastructure can be evaluated along with operational costs to perform a detailed cost analysis further.

The effects of vehicle's climate control system on EV energy consumption in different seasons are not considered in this study and is an area to be focused on in future. Detailed study on the influence of battery ambient temperature on battery discharge and degradation can also help in better understanding of the EV energy consumption. This study considers multiple arrivals of the same EV as different EV arrivals. Depending on the type of public facility, whether a gas station or a place of interest, multiple arrivals of the same EV makes a difference in the EV arrival pattern and future studies should consider its effect. 


\section{References}

[1] International Energy Outlook 2016, U.S. Energy Information Administration, Information publication, Pg 13, 2016 [2] U. Energy Information Administration, "Monthly Energy Review - July 2018,”2018.

[2] "Monthly Energy Review - July 2018," U. S. Energy Information Administration, Information publication, Table 2.5, Pg 39, 2018.

[3] Towards Green Growth, OECD Green Growth Studies, The Organisation for Economic Cooperation and Development (2011), OECD Publishing, Paris, 2011.

[4] Fast Facts-U.S.Transportation Sector Greenhouse Gas Emissions 1990 -2016, Office of Transportation and Air Quality, United States Environmental Protection Agency, July 2018.

[5] T.A.Boden, G.Marland, and R.J.Andres, (2017), National CO2 Emissions from Fossil-Fuel Burning, Cement Manufacture, and Gas Flaring: 1751-2014, Carbon Dioxide Information Analysis Center, Oak Ridge National Laboratory, U.S. Department of Energy, 2017.

[6] Alternative Fuels Data Center, Office of Energy Efficiency \& Renewable Energy, US Department of Energy, “How Do All-Electric Cars Work?,” 2018.

[7] M. C. Falvo, D. Sbordone, I. S. Bayram, and M. Devetsikiotis, "EV Charging Stations And Modes: International Standards," in 2014 International Symposium on Power Electronics, Electrical Drives, Automation and Motion, 2014, pp. 1134-1139.

[8] D.Gohlke, \& Y.Zhou, Impacts of Electrification of Light-Duty Vehicles in the United States, 2010 - 2017, Argonne National Lab. (ANL), Technical Report, Argonne, IL United States, Jan 2018. 
[9] R. R. Heffner, K. S. Kurani, and T. S. Turrentine, "Symbolism In California's Early Market For Hybrid Electric Vehicles," Transportation Research Part D: Transport and Environment, vol. 12, no. 6, pp. 396-413, Aug. 2007.

[10] Research and Innovative Technology Administration, U.S. Department Of Transportation, and Bureau of Transportation Statistics, "National Transportation Statistics," pp. 1-470, 2015.

[11] O. Egbue and S. Long, "Barriers to Widespread Adoption of Electric Vehicles: An Analysis of Consumer Attitudes and Perceptions,” Energy Policy, vol. 48, pp. 717-729, Sep. 2012.

[12] E. Wood, J. Neubauer, and E. Burton, "Measuring the Benefits of Public Chargers and Improving Infrastructure Deployments Using Advanced Simulation Tools Preprint," National Renewable Energy Laboratory, Information Publication, February, 2015.

[13] W. Sierzchula, S. Bakker, K. Maat, and B. Van Wee, "The Influence Of Financial Incentives And Other Socio-Economic Factors On Electric Vehicle Adoption,” Energy Policy, vol. 68, pp. 183-194, May 2014.

[14] E. Narassimhan and C. Johnson, "The Effect of State Incentives on Plug-in Electric Vehicle Purchases," National Renewable Energy Laboratory, Office of Energy Efficiency and Renewable Energy, U.S. Department of Energy, Information Publication, August 21, 2014.

[15] "Electric Vehicle Supply Equipment (EVSE) Rebate Program 2.0.” [Online]. Available: http://energy.maryland.gov/transportation/Pages/incentives_evserebate.aspx. [Accessed: 09-Jun-2018].

[16] S. Guner, A. Ozdemir, and G. Serbes, "Impact Of Car Arrival/Departure Patterns On EV 
Parking Lot Energy Storage Capacity,” in 2016 International Conference on Probabilistic Methods Applied to Power Systems (PMAPS), 2016, pp. 1-5.

[17] X. Xi, R. Sioshansi, and V. Marano, "Simulation-Optimization Model For Location Of A Public Electric Vehicle Charging Infrastructure," Transportation Research Part D: Transport and Environment, vol. 22, pp. 60-69, Jul. 2013.

[18] Y. Cao, S. Tang, C. Li, P. Zhang, Y. Tan, Z. Zhang, and J. Li, “An Optimized EV Charging Model Considering TOU Price and SOC Curve," IEEE Transactions on Smart Grid, vol. 3, no. 1, pp. 388-393, Mar. 2012.

[19] F. Kong, J. Jiang, Z. Ding, J. Hu, W. Guo, and L. Wang, “A Personalized Rolling Optimal Charging Schedule for Plug-In Hybrid Electric Vehicle Based on Statistical Energy Demand Analysis and Heuristic Algorithm," Energies, vol. 10, no. 9, p. 1333, Sep. 2017.

[20] S. Faridimehr, S. Venkatachalam, and R. B. Chinnam, "A Stochastic Programming Approach for Electric Vehicle Charging Network Design," IEEE Transactions on Intelligent Transportation Systems, pp. 1-13, 2018.

[21] M. Alizadeh, A. Scaglione, J. Davies, and K. S. Kurani, "A Scalable Stochastic Model for the Electricity Demand of Electric and Plug-In Hybrid Vehicles," IEEE Transactions on Smart Grid, vol. 5, no. 2, 2014.

[22] T. S. Hoon, K. L. Kee, and P. Singh, "Learning Mathematics Using Heuristic Approach," Procedia - Social and Behavioral Sciences, vol. 90, pp. 862-869, Oct. 2013.

[23] "Severe Weather Data | National Centers for Environmental Information (NCEI) formerly known as National Climatic Data Center (NCDC)." [Online]. Available: 
https://www.ncdc.noaa.gov/data-access/severe-weather. [Accessed: 11-Jun-2018].

[24] T. Aikoh, R. Abe, R. Kohsaka, M. Iwata, and Y. Shoji, "Factors Influencing Visitors to Suburban Open Space Areas near a Northern Japanese City,” Forests, vol. 3, no. 2, pp. 155165, Apr. 2012. 


\section{Appendix}

Private Sub CommandButton1_Click()

Dim min, max As Integer

Dim F As Single

Dim D, S, HF, i, j, 1, m, a, b As Integer

Dim k, c As Double

min = InputBox ("Minimum number of Electric Vehicles arriving per day? Please enter a number between 0 and 30,000", "Minimum arrivals") 'Asking Minimum number of Electric cars arriving per day $\max =$ InputBox("Maximum number of Electric Vehicles arriving per day? Please enter a number between 0 and 30,000", "Maximum arrivals") 'Asking Maximum number of Electric cars arriving per day $\mathrm{F}=$ InputBox("Probability of Tesla ${ }^{\circledR}$ Vehicles arriving round the year? Please enter a fraction between 0 and 1", "Fraction of Tesla ${ }^{\circledR}$ vehicles ") 'Asking fraction of Tesla® cars arriving

$\mathrm{a}=\min$

$\mathrm{b}=\max$

$\mathrm{b}=(\mathrm{a}+\mathrm{b}) / 2$

Worksheets(1).Range("F:G") = ""

Worksheets $(1) \cdot$ Cells $(1,1)=$ "Date"

Worksheets(1).Cells (1, 2) = "Day"

Worksheets(1).Cells $(1,3)=$ "Weather Factor"

Worksheets(1).Cells (1, 4) = "Holiday Factor"

Worksheets(1).Cells(1, 5) = "No. of Cars"

Worksheets(1).Cells $(1,6)=$ "No. of Tesla®s"

Worksheets(1).Cells(1, 7) = "No. of Regular"

Worksheets $(1) \cdot \operatorname{Cells}(5,10)=\min$

Worksheets $(1) \cdot \operatorname{Cells}(6,10)=\max$ 


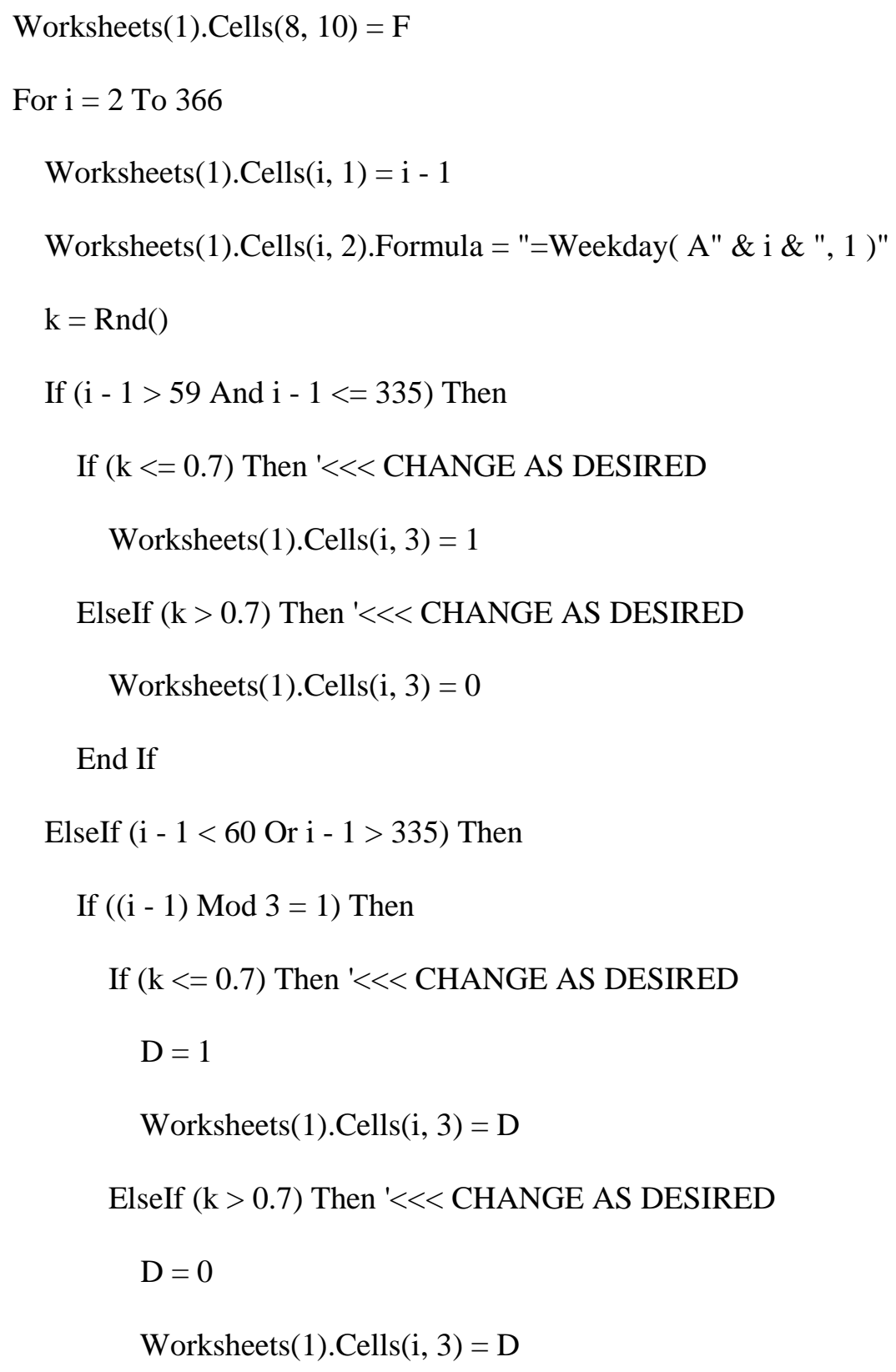


Worksheets(1).Cells(i, 4).Formula = "=IF(OR(AND(99<A" \& i \& ",A" \& i \& "<111),AND(121<A" \& i \& ",A" \& i \& "<214),AND(320<A" \& i \& ",A" \& i \& "<331),B" \& i \& "=6,B" \& i \& "=7,COUNTIF( $\$$ K $\$ 21: \$ K \$ 46, A "$ \& i \& "))=TRUE,1,0)"

If Worksheets(1).Cells(i, 3$)=0$ Then

Worksheets $(1) \cdot \operatorname{Cells}(\mathrm{i}, 5)=\min$

ElseIf Worksheets(1).Cells(i, 3) $=1$ And Worksheets(1).Cells(i, 4) $=0$ Then

Worksheets(1).Cells(i, 5) = Application.WorksheetFunction.RoundUp(b, 0)

ElseIf Worksheets(1).Cells(i, 3) $=1$ And Worksheets(1).Cells(i, 4) $=1$ Then

Worksheets(1).Cells $(\mathrm{i}, 5)=\max$

End If

$1=1$

$\mathrm{m}=1$

For $\mathrm{j}=1$ To Worksheets(1).Cells $(\mathrm{i}, 5)$

$\mathrm{c}=\operatorname{Rnd}()$

If $\mathrm{c}<=(1-\mathrm{F})$ Then $' \ll<$ CHANGE AS DESIRED

Worksheets(1).Cells (i, 7) = 1

$1=1+1$

ElseIf $(\mathrm{c}>(1-\mathrm{F}))$ Then $1<<<$ CHANGE AS DESIRED

Worksheets $(1) \cdot \operatorname{Cells}(\mathrm{i}, 6)=\mathrm{m}$

$\mathrm{m}=\mathrm{m}+1$

End If

Next j

If Worksheets(1).Cells $(i, 6)=$ "" Then

Worksheets(1).Cells $(i, 6)=0$

End If

If Worksheets(1).Cells(i, 7) = "" Then 
Worksheets (1).Cells $(\mathrm{i}, 7)=0$

End If

Next i

End Sub

Private Sub CommandButton2_Click()

Dim i, a, cars, k, 1 As Integer

Dim j As Long

Dim Low As Double

Dim High As Double

Dim Wk As Workbook

$\mathrm{a}=2$

Low $=11^{\prime} \ll<$ CHANGE AS DESIRED

High $=24{ }^{\prime}<<<$ CHANGE AS DESIRED

ActiveWorkbook.Sheets.Add After:=Worksheets(Worksheets.Count)

Sheets(ActiveSheet.Name).Name = "Regular Ex1"

ActiveWorkbook.Sheets.Add After:=Worksheets(Worksheets.Count)

Sheets(ActiveSheet.Name).Name = "Regular Numbers"

Worksheets("Regular Numbers").Cells(1, 1) = "Arrival time (hours)"

Worksheets("Regular Numbers").Cells(1, 3) = "Inter Arrival time (hours)"

Worksheets("Regular Numbers").Cells( 1,8$)=$ "Date"

Worksheets("Regular Numbers").Cells(1, 9) = "No. of Regular cars"

For $\mathrm{i}=1$ To 365

Worksheets("Regular Numbers").Cells $(\mathrm{i}+1,8)=\mathrm{i}$

Worksheets("Regular Numbers").Cells $(i+1,10)=$ "--------->"

Worksheets("Regular Numbers").Cells $(i+1,9)=$ Worksheets(1).Cells $(i+1,7)$ 
cars $=$ Worksheets("Regular Numbers").Cells $(i+1,9)$

If $($ cars $=0)$ Then

GoTo ErrorHandler:

Else

$$
\text { For } \mathrm{j}=1 \text { To cars }
$$

Worksheets("Regular Numbers").Cells $(\mathrm{i}+1, \mathrm{j}+10)=\operatorname{Round}((\mathrm{i}-1) * 24+($ High - Low +1$) *$

$\operatorname{Rnd}(), 0)$

Worksheets("Regular Ex1").Cells(j, 1) = Worksheets("Regular Numbers").Cells $(i+1, j+10)$

\section{Next $\mathrm{j}$}

Worksheets("Regular Ex1").Range("A1:A" \& j).Sort Key1:=Worksheets("Regular Ex1").Range("A1:A"

\& j), Order1:=xlAscending, Header:=xlNo

For $\mathrm{j}=1$ To cars

Worksheets("Regular Numbers").Cells(i + 1, j + 10) = Worksheets("Regular Ex1").Cells(j, 1)

Worksheets("Regular Numbers").Cells $(\mathrm{a}+1,1)=$ Worksheets("Regular Numbers").Cells $(\mathrm{i}+1, \mathrm{j}+$

10)

Worksheets("Regular Ex1").Cells(j, 1) = "'

Worksheets("Regular Numbers").Cells(a + 1, 3) = Worksheets("Regular Numbers").Cells(a + 1, 1) -

Worksheets("Regular Numbers").Cells(a, 1)

$\mathrm{a}=\mathrm{a}+1$

Next j

End If

Worksheets("Regular Numbers").Cells(2, 3) = 0

ErrorHandler:

Next i

Worksheets("Regular Ex1").Delete

Worksheets(1).Activate 
End Sub

Private Sub CommandButton3_Click()

Dim i, a, cars, k, 1 As Integer

$\operatorname{Dim} \mathrm{j}$ As Long

Dim Low As Double

Dim High As Double

Dim Wk As Workbook

$\mathrm{a}=2$

Low $=11^{\prime} \ll<$ CHANGE AS DESIRED

High $=24{ }^{\prime}<<<$ CHANGE AS DESIRED

ActiveWorkbook.Sheets.Add After:=Worksheets(Worksheets.Count)

Sheets(ActiveSheet.Name).Name = "Tesla ${ }^{\circledR}$ Ex1"

ActiveWorkbook.Sheets.Add After:=Worksheets(Worksheets.Count)

Sheets(ActiveSheet.Name).Name = "Tesla® Numbers"

Worksheets("Tesla® Numbers").Cells $(1,1)=$ "Arrival time (hours)"

Worksheets("Tesla® Numbers").Cells(1, 3) = "Inter Arrival time (hours)"

Worksheets("Tesla ${ }^{\circledR}$ Numbers").Cells $(1,8)=$ "Date"

Worksheets("Tesla® Numbers").Cells $(1,9)$ = "No. of Tesla® cars"

For $\mathrm{i}=1$ To 365

Worksheets("Tesla® Numbers").Cells $(\mathrm{i}+1,8)=\mathrm{i}$

Worksheets("Tesla ${ }^{\circledR}$ Numbers").Cells $(\mathrm{i}+1,10)$ = "--------->"

Worksheets("Tesla® Numbers").Cells $(i+1,9)=$ Worksheets(1).Cells $(i+1,6)$

cars $=$ Worksheets $(" T e s l a ® ~ N u m b e r s ") . C e l l s(i+1,9)$

If $($ cars $=0)$ Then

GoTo ErrorHandler:

Else 
For $\mathrm{j}=1$ To cars

Worksheets("Tesla® Numbers").Cells $(\mathrm{i}+1, \mathrm{j}+10)=\operatorname{Round}((\mathrm{i}-1) * 24+(\operatorname{High}-\operatorname{Low}+1) *$

$\operatorname{Rnd}(), 0)$

Worksheets("Tesla® Ex1").Cells(j, 1) = Worksheets("Tesla® Numbers").Cells(i + 1, j + 10)

Next j

Worksheets("Tesla® Ex1").Range("A1:A" \& j).Sort Key1:=Worksheets("Tesla® Ex1").Range("A1:A" \&

j), Order1:=xlAscending, Header:=xlNo

For $\mathrm{j}=1$ To cars

Worksheets("Tesla® Numbers").Cells(i + 1, j + 10) = Worksheets("Tesla® Ex1").Cells(j, 1)

Worksheets("Tesla® Numbers").Cells $(\mathrm{a}+1,1)=$ Worksheets("Tesla ${ }^{\circledR}$ Numbers").Cells( $\mathrm{i}+1, \mathrm{j}+$

10)

Worksheets("Tesla® Ex1").Cells(j, 1) = ""

Worksheets("Tesla® Numbers").Cells $(\mathrm{a}+1,3)=$ Worksheets("Tesla ${ }^{\circledR}$ Numbers").Cells(a + 1, 1) -

Worksheets("Tesla® Numbers").Cells(a, 1)

$\mathrm{a}=\mathrm{a}+1$

Next $\mathrm{j}$

End If

Worksheets("Tesla® Numbers").Cells(2, 3) =0

ErrorHandler:

Next i

Worksheets("Tesla® Ex1").Delete

Worksheets("Monthly Data").Activate

End Sub

Private Sub CommandButton4_Click()

Worksheets(1).Range("A1:G366").ClearContents 


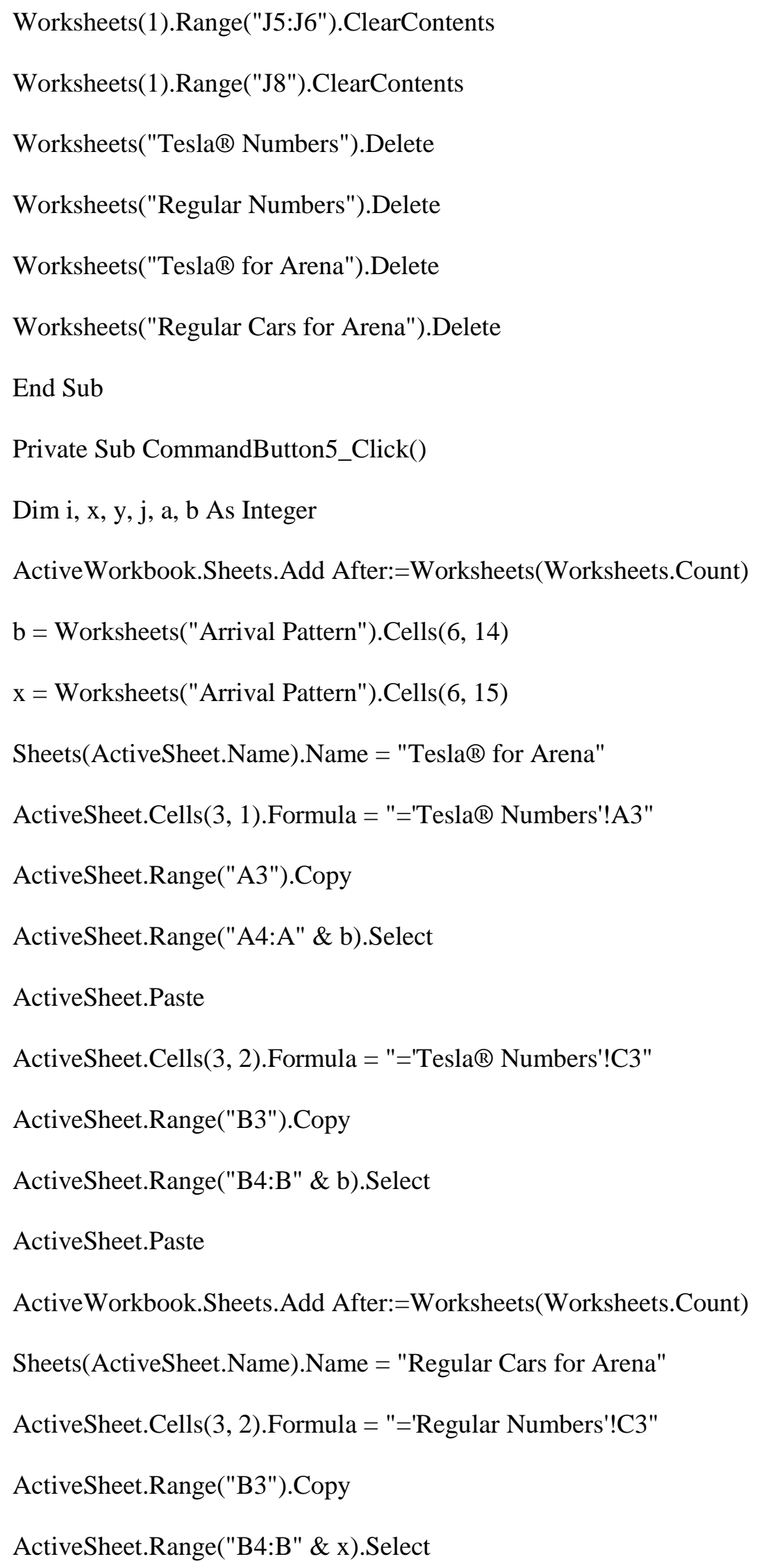




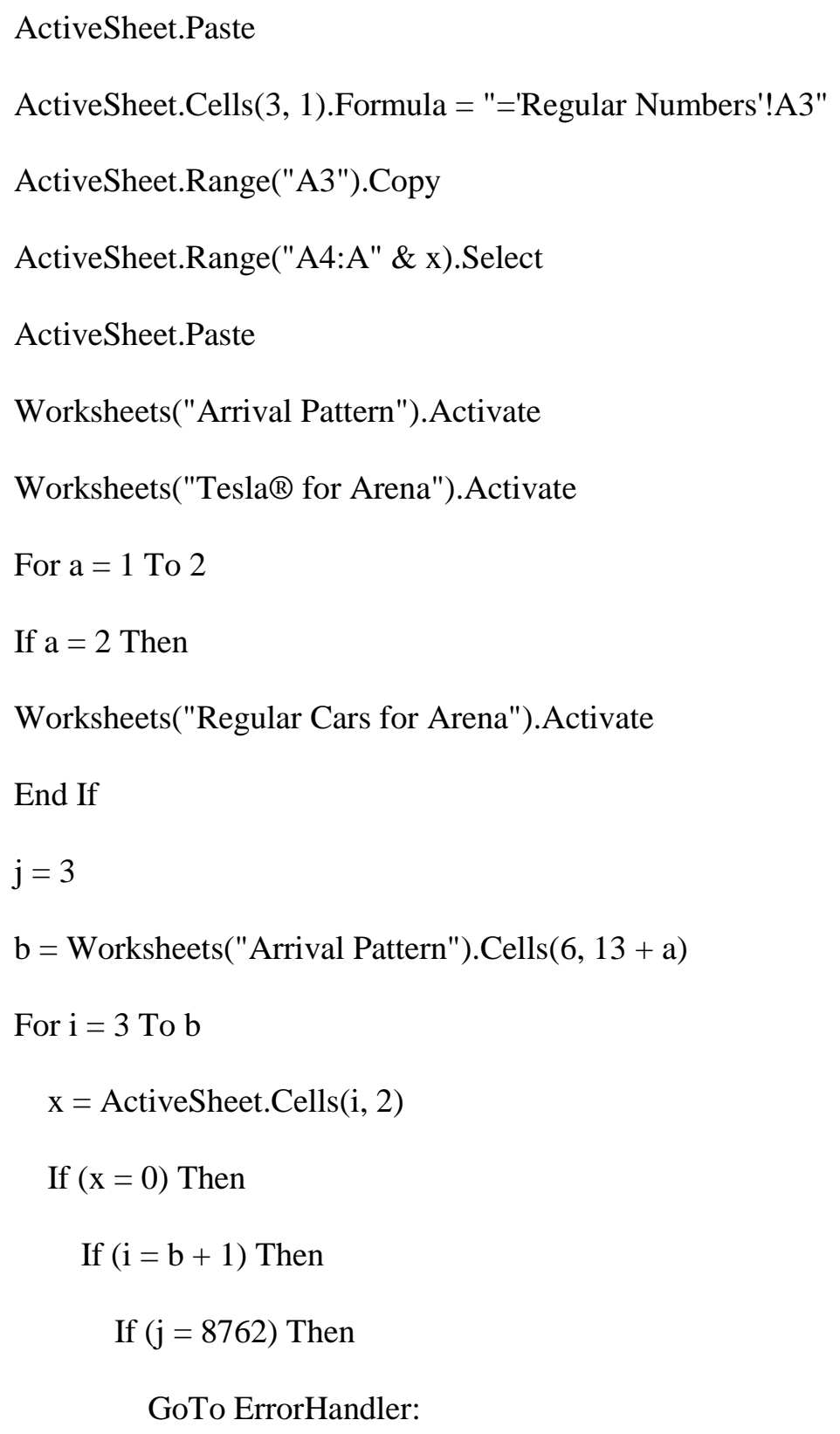


End If

Else

For $\mathrm{y}=1$ To $\mathrm{x}-1$

ActiveSheet.Cells $(\mathrm{j}, 3)=0$

$\mathrm{j}=\mathrm{j}+1$

Next y

If $(x>0)$ Then

ActiveSheet.Cells $(\mathrm{j}, 3)=1$

$\mathrm{j}=\mathrm{j}+1$

End If

End If

Next $i$

ErrorHandler:

Next a

Worksheets("Tesla® for Arena").Cells $(1,3)=$ "Tesla® Arena Input"

Worksheets("Regular Cars for Arena").Cells $(1,3)=$ = Schneider® Arena Input"

End Sub 